\title{
Locus-specific variation in phosphorylation state of RNA polymerase II in vivo: correlations with gene activity and transcript processing
}

\author{
John R. Weeks, ${ }^{1}$ Steven E. Hardin, ${ }^{1,2}$ Jianjun Shen, Jae Moon Lee, and Arno L. Greenleaf ${ }^{3}$ \\ Department of Biochemistry, Duke University Medical Center, Durham, North Carolina 27710 USA
}

\begin{abstract}
To investigate functional differences between RNA polymerases IIA and IIO (Pol IIA and Pol II0), with hypoand hyperphosphorylated carboxy-terminal repeat domains (CTDs), respectively, we have visualized the in vivo distributions of the differentially phosphorylated forms of Pol II on Drosophila polytene chromosomes. Using phosphorylation state-sensitive antibodies and immunofluorescence microscopy with digital imaging, we find Pol IIA and Pol IIO arrayed in markedly different, locus- and condition-specific patterns. Major ecdysone-induced puffs, for example, stain exclusively for Pol IIO, indicating that hyperphosphorylated Pol II is the transcriptionally active form of the enzyme on these genes. In striking contrast, induced heat shock puffs stain strongly for both Pol IIA and Pol IIO, suggesting that heat shock genes are transcribed by a mixture of hypo- and hyperphosphorylated forms of Pol II. At the insertion sites of a transposon carrying a hybrid hsp 70-lacZ transgene, we observe only Pol IIA before heat shock induction, consistent with the idea that Pol II arrested on the hsp70 gene is form IIA. After a 90-sec heat shock, we detect heat shock factor (HSF) at the transposon insertion sites; and after a 5-min shock its spatial distribution on the induced transgene puffs is clearly resolved from that of Pol II. Finally, using antibodies to hnRNP proteins and splicing components, we have discerned an apparent overall correlation between the presence and processing of nascent transcripts and the presence of Pol IIO.
\end{abstract}

[Key Words: RNA polymerase IIA/II0; CTD phosphorylation; transcription factors; in situ localization; immunofluorescence microscopy; digital imaging]

Received July 28, 1993; revised version accepted September 29, 1993.

The carboxy-terminal repeat domain (CTD) of the largest subunit of RNA polymerase II (Pol II) is an unusual entity composed of multiple repeats of the 7-amino-acid consensus sequence YSPTSPS (for review, see Corden 1990; Young 1991). The number of repeats ranges from 26 in yeast, to 42 in Drosophila, to 52 in mammals. The CTD has been shown to carry out essential in vivo roles in yeast (Nonet et al. 1987), Drosophila (Zehring et al. 1988), and mammalian cells (Bartolomei et al. 1988), but precisely what those roles are is not well understood. Suggested roles for the CTD include interacting with transcription initiation factors, serving as a molecular "cowcatcher" to facilitate movement of polymerase on chromatin templates, providing a link between transcription and RNA processing, and localizing polymerase to specific nuclear compartments (Corden 1990).

Most investigations implicate the CTD in a role re-

\footnotetext{
${ }^{1}$ These authors contributed equally to this paper.

${ }^{2}$ Present address: Department of Math and Science, Spalding University, Louisville, Kentucky 40203 USA.

${ }^{3}$ Corresponding author.
}

lated to transcription initiation. For example, Pol II carrying altered CTDs responds differently to certain wildtype and mutant transcriptional regulators in vivo (Allison et al. 1988; Scafe et al. 1990; Peterson et al. 1991), suggesting that the CTD may be involved in receiving regulatory signals at certain promoters. In vivo and in vitro experiments suggest that these responses might be mediated through the TATA-binding protein (TBP) component of TFIID (Koleske et al. 1992; Usheva et al. 1992; Thompson et al. 1993). On the other hand, the precise nature of the CTD involvement in initiation is not known, and questions of its generality are raised by in vitro results demonstrating that for a number of different promoters Pol II lacking a CTD can function normally in factor-dependent promoter recognition and transcription initiation (Zehring et al. 1988; Kim and Dahmus 1989; Thompson et al. 1989; Buratowski and Sharp 1990; Zehring and Greenleaf 1990; Buermeyer et al. 1992).

A notable feature of the CTD is that it can be found in vivo in a hyperphosphorylated form (for review, see Dahmus and Dynan 1992) that carries phosphates predominantly on serine, with minor amounts on threonine. The 
unphosphorylated form of the largest subunit is called subunit IIa, and the form with a hyperphosphorylated CTD is called IIo; these forms can be distinguished by their different mobilities in SDS gels, where form IIo displays a mobility markedly less than that of IIa. The enzymes containing subunit forms IIa and Ilo are called Pol IIA and Pol IIO, respectively.

Evidence for functional differences between RNA Pol IIA and Pol IIO was obtained by photoaffinity cross-linking experiments in HeLa extracts or nuclei (Bartholomew et al. 1986; Cadena and Dahmus 1987). Nascent RNA chains were found to be preferentially linked to IIo rather than IIa, arguing that in HeLa cells elongating Pol II is predominantly IIO. Consistent with the cross-linking results, several in vitro studies indicate that Pol IIA participates in preinitiation complex formation and that before or concurrent with initiation of RNA synthesis IIA is converted to IIO by CTD phosphorylation (Laybourn and Dahmus 1990; Lu et al. 1991; Chesnut et al. 1992). This would suggest that a CTD kinase activity should be part of the preinitiation complex. A purified transcription factor called TFIIH (or BTF2) in humans (Lu et al. 1992), $\delta$ in rats (Serizawa et al. 1992), or factor b in yeast (Gileadi et al. 1992) appears to have an associated CTD kinase activity. Some of the results in these studies, however, indicate that the question of how CTD phosphorylation is related mechanistically to initiation has yet to be resolved. For example, it was found that Pol IIB, which lacks the CTD, can replace Pol IIA in the in vitro human system, confirming that at least for some promoters preinitiation complex formation and initiation can occur even in the absence of the CTD. Furthermore, Pol IIB still requires TFIIH; thus, this factor must perform a role or roles in addition to CTD phosphorylation (Lu et al. 1992). Finally, a recent study has functionally uncoupled CTD phosphorylation from transcription initiation (and elongation) in vitro (Serizawa et al. 1993).

In attempts to better understand CTD phosphorylation and how it may modulate the properties of Pol II, a number of investigators have sought to identify and purify CTD kinases. For example, we previously purified a yeast CTD kinase based on its ability to hyperphosphorylate and retard the mobility of a fusion protein carrying a full-length CTD (Lee and Greenleaf 1989). Antibodies prepared against subunits of this yeast enzyme were used to clone the CTK1 gene that encodes its $\alpha$-subunit; sequence analysis indicated that this subunit is probably catalytic (Lee and Greenleaf 1991). Gene disruption studies revealed that cells lacking a functional CTK1 gene (and the CTK1-containing CTD kinase) display a slowgrowth, cold-sensitive lethal phenotype; thus the CTK1containing CTD kinase (CTDK-I) is essential for normal growth of yeast. Furthermore, although mutant cells growing at the permissive temperature contain phosphorylated forms of the RNA Pol II largest subunit, the phosphorylation state of the CTD appears to be abnormal (Lee and Greenleaf 1991). Although these data do not relate this kinase to a particular step in the transcription cycle, they suggest strongly that yeast CTDK-I plays a role in CTD phosphorylation in vivo. They suggest fur- ther that other CTD kinases exist in yeast; one such kinase that appears to be distinct from CTDK-I might be the activity associated with transcription factor $b$.

Additional CTD kinases that have been purified extensively are a template-associated protein kinase from HeLa cells (Dvir et al. 1993, and references therein), CTD kinases KI, KII, and KIII from Aspergillis (Stone and Reinberg 1992), kinases CTDK1 and CTDK2 from HeLa cells (Payne and Dahmus 1993), and cdc2-containing CTD kinases E1 and E2 from mouse (Zhang and Corden 1991, and references therein). Several of these enzymes display properties suggestive of physiological roles, but none has yet been demonstrated to function in CTD phosphorylation in vivo. Still other CTD kinase activities have been identified in extracts from mammalian (Stevens and Maupin 1989; Legagneux et al. 1990) or plant (Guilfoyle 1989) cells.

The observations summarized above have not yet led to a clear picture of CTD function and phosphorylation, especially in vivo. Clarifying the situation will certainly require more information about the in vivo behavior of the different forms of Pol II in different cells, on different genes, and under different physiological conditions. For example, the HeLa photo cross-linking results mentioned above did not completely exclude the possibility that IIA as well as IIO can be transcriptionally active for at least two reasons. First, some RNA was cross-linked to IIA. Second, HeLa cells appear to contain very little IIA, in contrast to a number of other cell types (e.g., Kim and Dahmus 1986; Kolodziej et al. 1990; Lee and Greenleaf 1991; also see below); it is possible that similar experiments in a cell type with a higher proportion of IIA would yield more nascent RNA linked to this form of polymerase. Similarly, most of the studies relating CTD phosphorylation to initiation in vitro have used HeLa components and a very limited number of promoters; thus, the generality of the results is not known. Finally, there is currently insufficient information to understand the functional or structural relationships among the several CTD kinases identified in different systems.

We believed that assessing the association of RNA polymerase forms IIA and IIO with specific chromosomal sites in vivo could provide a needed base line of Pol II behavior and contribute to an eventual elucidation of the physiological significance of CTD phosphorylation. A good experimental system for visualizing locus-specific distributions of differentially phosphorylated forms of Pol II appeared to be the giant polytene chromosomes found in Drosophila larval salivary glands. Chromosomal proteins can be covalently cross-linked in situ to these chromosomes and observed in the light microscope by immunofluorescence or immunochemical techniques (Greenleaf et al. 1976; Silver and Elgin 1976; Zink et al. 1991; for review, see Clark et al. 1991). The patterns of transcriptional activity for many loci of the polytene chromosomes have been documented extensively, originally as manifested by cytologically visible puff formation (e.g., Ritossa 1962; Ashburner and Richards 1976) and more recently by molecular techniques (e.g., Ashburner and Bonner 1979; Burtis et al. 1990; Segraves and 
Hogness 1990; Rabindran et al. 1993). This information base seemed to provide the potential for correlating the activity state of certain loci with the form of Pol II found there. In addition, comparing chromosomal distributions of Pol IIA or IIO with those of other chromosomal proteins could potentially be used to test predictions about or reveal unanticipated aspects of Pol II behavior in vivo.

In this paper we describe preparing antibodies directed against the nonphosphorylated and the hyperphosphorylated CTD and using them to detect and characterize locus-specific in vivo distributions of Pol IIA and IIO by immunofluorescence microscopy with digital imaging. We also present experiments comparing these distributions with those of several other nuclear proteins involved in transcriptional regulation and pre-mRNA processing.

\section{Results}

\section{Phosphorylation state-specific anti-CTD antibodies}

To investigate the in vivo chromosomal distributions of Drosophila RNA polymerase forms IIA and II0, we affinity purified goat antibodies against the nonphosphorylated CTD and rabbit antibodies against the hyperphosphorylated CTD (Materials and methods). We tested the specificity of each antibody initially using Western blots of quickly prepared embryo extracts. These extracts contain roughly equivalent amounts of Pol IIA and IIO, as revealed by an antibody (anti-exon2) that detects both forms equally because it reacts with determinants near the amino terminus of the subunit (Fig. 1, lane 1). As shown in Figure 1 (lane 3), the anti-phosphoCTD anti-

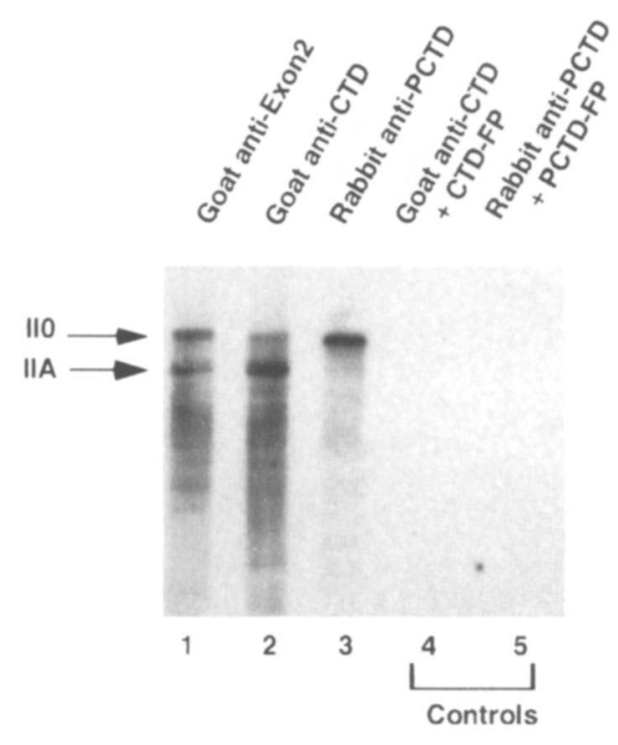

Figure 1. Western blot of quickly prepared Drosophila embryo extracts. Identical membrane strips were reacted with primary antibodies as indicated. For the controls in lanes 4 and 5, the primary antibody was preincubated with excess cognate fusion protein for $1 \mathrm{hr}$ at room temperature before reacting with the membrane. bodies (anti-PCTD) are exquisitely specific for the hyperphosphorylated, slower-migrating (IIo) form of the largest Pol II subunit (note that other experiments demonstrated that they do not react significantly with any lower molecular weight polypeptides that ran off the gel shown here). Likewise, the anti-CTD antibodies (antiCTD) are highly selective for the nonphosphorylated, faster-migrating (IIa) form, although they also react to some degree with a band at the Ilo position (lane 2).

To characterize further the selectivity of the two antibody preparations, we tested their reactivities toward differentially phosphorylated forms of a CTD fusion protein. First, we treated a hyperphosphorylated CTD fusion protein with increasing amounts of alkaline phosphatase to reproduce an analog of the Ilo $\rightarrow$ IIa SDS gel mobility shift (Fig. 2A). Treatment with a low amount of phosphatase (lane 2) did not cause a noticeable mobility increase, nor did treatment with 10 times as much (lane 3 ), whereas treatment with 25 times as much or more (lanes 4-7) caused much or all of the fusion protein to move with increased mobility. Figure $2 B$ shows that treatment with even the lowest amount of alkaline phosphatase greatly diminished the reactivity of the antiPCTD antibodies toward the phosphorylated fusion protein (lane 2) and treatment with 10 times as much nearly abolished the reactivity (lane 3 ). In neither case did the mobility of the fusion protein increase appreciably, indicating that the antibodies are reactive only toward the most highly phosphorylated forms of the CTD and, incidentally, underscoring the complex relationship between the SDS mobility of the CTD fusion protein and its level of phosphorylation. No reactivity was observed with fusion protein exposed to higher amounts of phosphatase (lanes 4-7), treatment that induced substantial or complete mobility shift.

Figure 2C demonstrates the complementary specificity of the anti-CTD antibodies. These antibodies barely reacted with the hyperphosphorylated fusion protein (lane 1), but they showed some reactivity after a partial dephosphorylation that did not result in a mobility increase (lane 2). As more phosphates were removed, and especially after the mobility of the fusion protein increased, the anti-CTD reactivity increased further.

These results indicate that the anti-PCTD antibodies are quite selective for the hyperphosphorylated form(s) of the CTD; for convenience we refer to them as anti-II0, realizing the inadequacy of the IIO/IIA nomenclature (e.g., Corden 1990; Lee and Greenleaf 1991; Dahmus and Dynan 1992). The anti-CTD antibodies react only barely with the most highly phosphorylated forms, but they do show a reactivity toward partially dephosphorylated forms that increases as the extent of dephosphorylation increases; they react most strongly with the nonphosphorylated CTD. In this paper we refer to them as antiIIA.

Localization of RNA Pol IIA and Pol IIO on polytene chromosomes: major developmental puffs contain IIO

To analyze the in vivo distributions of RNA polymerase 


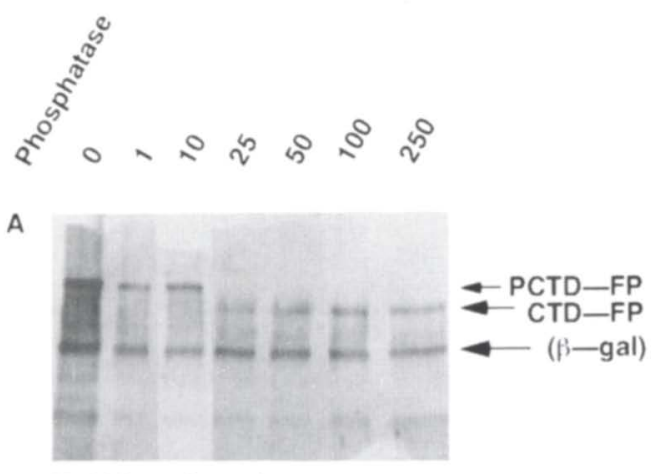

Rabbit anti-fi-gal

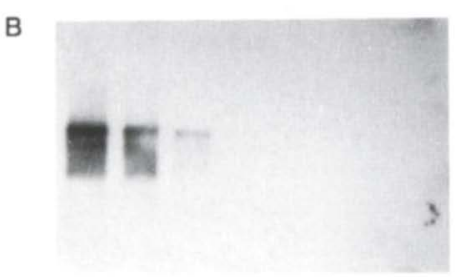

Rabbit anti-PCTD

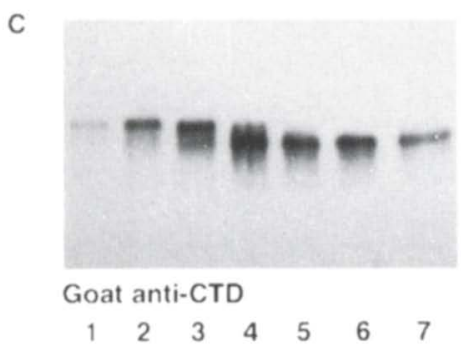

Figure 2. Phosphorylation state-dependent antibody reactivities. Phosphorylated CTD fusion protein (PCTD-FP) was treated with increasing amounts of alkaline phosphatase, and replicate samples were electrophoresed in three separate SDS gels and blotted to nitrocellulose. The relative amounts of phosphatase are indicated above the lanes. (Lane 1) 0 units; (lane 2) 0.025 units; (lane 3) 0.25 units, etc. (A) Blot reacted with rabbit anti$\beta$-galactosidase IgG and developed with BCIP/NBT (Materials and methods|. Note that for this gel only, lane 1 contained $50 \mathrm{ng}$ of fusion protein, whereas all other lanes contained $25 \mathrm{ng} .(B)$ Blot reacted with rabbit anti-PCTD IgGs and developed by use of chemiluminescence. $(C)$ Blot reacted with goat anti-CTD IgGs and developed by use of chemiluminescence.

forms IIA and IIO, we first fixed chromosomal proteins in situ by treating salivary glands with formaldehyde and then made squash preparations of the fixed polytene chromosomes for reacting with the antibodies (see Materials and methods).

Control indirect immunofluorescence microscopy experiments, in which one primary antibody and both chromophore-tagged secondary antibodies were included, confirmed that we could uniquely detect each form of the enzyme and also that the image in each case was dependent on the primary antibody, with virtually no background contributed by the secondary antibodies (not shown).

To compare directly the distribution of differentially phosphorylated forms of RNA Pol II, we carried out double-label antibody staining. As shown in Figure 3, the antibodies revealed distinct but overlapping distributions. Anti-IIA (green signal) and anti-IIO (red signal) stain many distinct sites (red or green), as well as common sites (yellow or orange) distributed widely on all chromosome arms (only the distal half of the X chromosome shown here). Given the antibody specificity tests described earlier, we infer that the red sites contain only highly phosphorylated Pol II and that the green sites contain virtually no highly phosphorylated Pol II. The sites of intermediate color presumably contain a mixture of highly phosphorylated enzyme and either unphosphorylated or incompletely phosphorylated enzyme.

The characteristic developmental puff at 2B5 stains primarily red (IIO), as do several additional sites, some of which appear puffed and some of which do not. The 2B5 puff, which is the site of the Broad Complex and is induced by the molting hormone ecdysone (e.g., DiBello et al. 1991), consistently stains with anti-IIO at puff stages when it is known to be active. At these same times, the extreme tip of the chromosome stains reproducibly only green (IIA), and there are other only green sites as well. As mentioned, there are yet other sites that stain with both antibodies, giving intermediate colors in this overlay view; the one indicated by a downward arrow, for

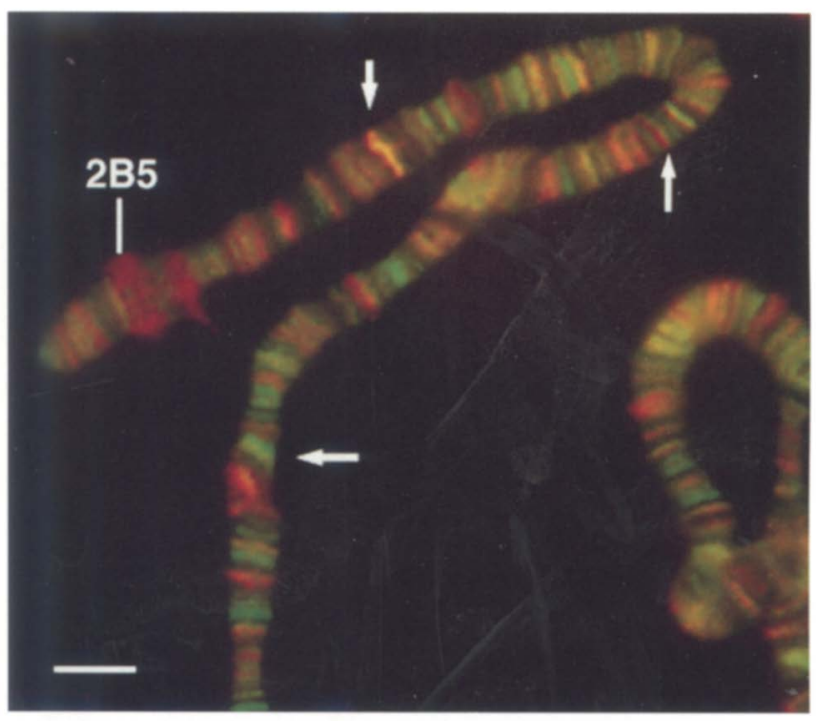

Figure 3. Distinct distributions of Pol IIA and Pol IIO on polytene chromosomes. Formaldehyde-fixed chromosome preparation reacted with goat anti-CTD (anti-IIA) and rabbit antiPCTD (anti-IIO) antibodies and visualized by indirect immunofluorescence and digital imaging (see Materials and methods). This overlay of anti-CTD (green) and anti-PCTD (red) images shows principally the distal half of the $\mathrm{X}$ chromosome. Arrows indicate examples of red signals not obviously puffed (upward arrow), green signals (leftward arrow) and mixed signals (downward arrow). (2B5) An early ecdysone-induced puff. Bar, $5 \mu \mathrm{m}$. 
example, is observed very reproducibly (see Fig. 6b-e, below).

Some of the most dramatic ecdysone-induced puffs are the so-called Chinese lanterns at 74EF and 75B, which are induced by the ecdysone titer increase that initiates molting (Ashburner and Richards 1976; Burtis et al. 1990; Segraves and Hogness 1990). Part of a chromosome $3 \mathrm{~L}$ displaying these large puffs is shown in Figure 4. Figure $4 \mathrm{a}$ shows that the anti-IIA antibodies are virtually unreactive toward the $74 \mathrm{EF}$ and $75 \mathrm{~B}$ puffs, whereas they stain many other nonpuff sites very strongly, as seen previously; in addition, they react weakly with other ecdysone-induced puffs present at this puff stage. In marked contrast, Figure $4 \mathrm{~b}$ shows that the $74 \mathrm{EF}$ and $75 \mathrm{~B}$ puffs are stained intensely by anti-IIO antibodies, as are the other prominent puffs; as described above, many other bands are also stained.

The overlay shown in Figure 4c allows direct comparisons of the IIA and IIO patterns. This view confirms the impressions from Figure $4 a$ and $b$, that the largest ecdysone puffs are stained almost exclusively by anti-IIO and the other obvious puffs are stained more strongly by antiIIO than by anti-IIA. Where a prominent puff stains with both antibodies, it is also apparent that the two patterns are spatially distinct. The overlay view also reiterates the observation that a prevalent class of nonpuffed sites appears to contain only Pol IIA (green), another class contains both IIA and IIO (yellow or orange), and a third class contains only IIO (red).
The results to this point indicate that the most obvious developmental puffs contain primarily RNA Pol IIO. Because puffing at these loci is a consequence of transcription (e.g., Burtis et al. 1990; Segraves and Hogness 1990), it seems reasonable to conclude that the transcription at these sites is carried out by Pol IIO. (It should be pointed out here that we have not yet presented direct evidence that any particular locus was actually transcriptionally active at the moment the chromosome preparation was made). At this point, we cannot say whether the other not obviously puffed red (IIO only), green (IIA only), or orange/yellow (IIO and IIA) sites are transcriptionally active. Thus, the results do not reveal whether, for example, Pol IIA is also transcriptionally competent.

\section{Heat shock puffs contain both Pol IIA and Pol IIO}

To observe a different set of genes, known to be active at the moment of sample preparation, we chose the heat shock loci. Incubation of larvae at $37^{\circ} \mathrm{C}$ rapidly induces a set of nine major heat shock puffs that represent sites of newly activated transcription (for review, see Ashburner and Bonner 1979). Anti-IIA and anti-IIO staining of endogenous heat shock puffs is shown in Figure 5. In marked contrast to the developmental puffs, the heat shock puffs react strongly with both anti-IIA and antiII0. The uniformity of the staining in the puffs suggests that the heat shock loci are being transcribed by both
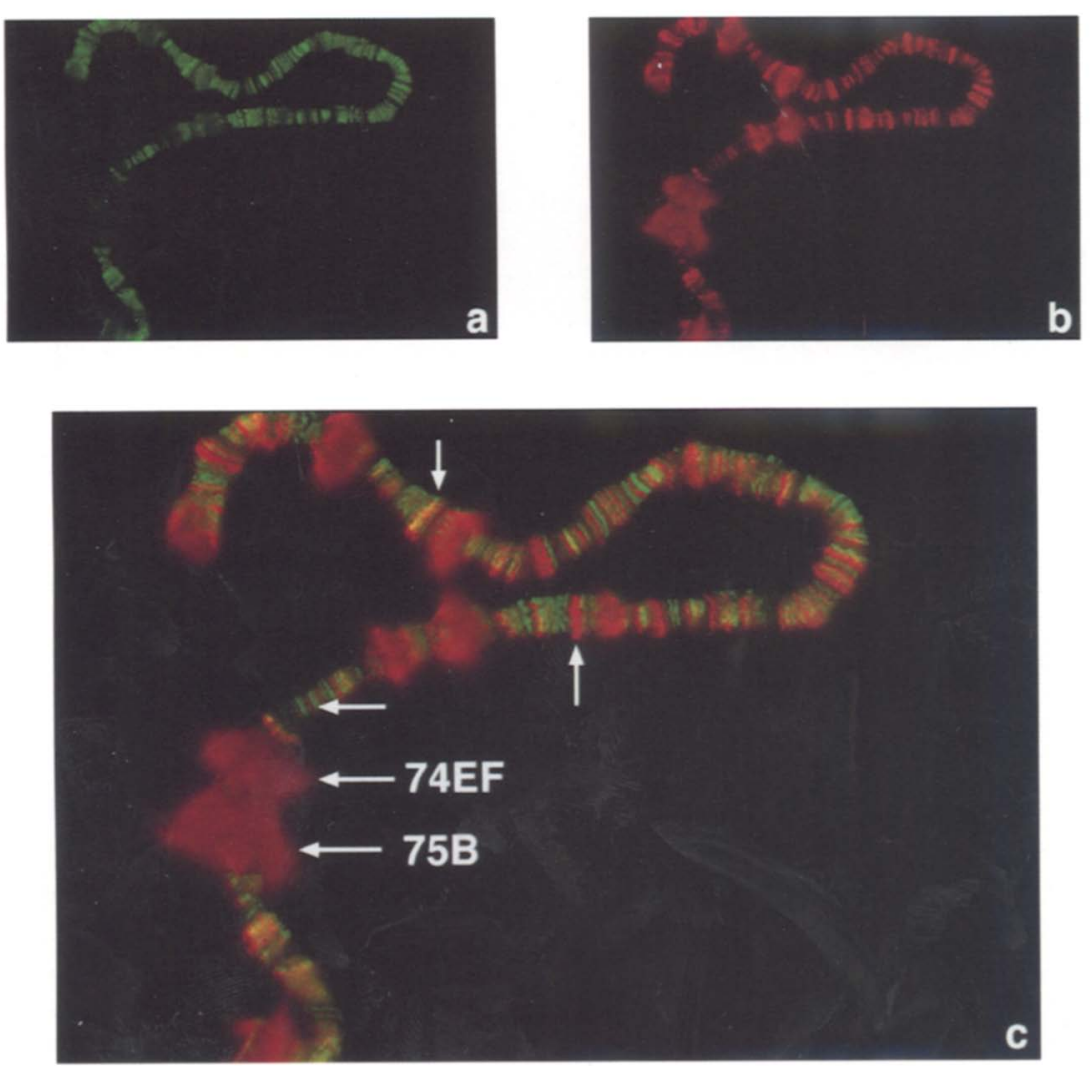

Figure 4. RNA Pol IIO and Pol IIA on major ecdysone puffs. Distal three-fourths of chromosome $3 \mathrm{~L}$ from a preparation reacted with goat anti-IIA and rabbit anti-IIO antibodies. $|a|$ Anti-IIA signal; $(b)$ anti-IIO signal; $(c)$ overlay of $a$ and $b$. Major early ecdysone puffs at 74EF and 75B (Chinese lanterns) are indicated, as are examples of sites not obviously puffed that stain red (upward arrow), green (leftward arrow), and mixed (downward arrow). 

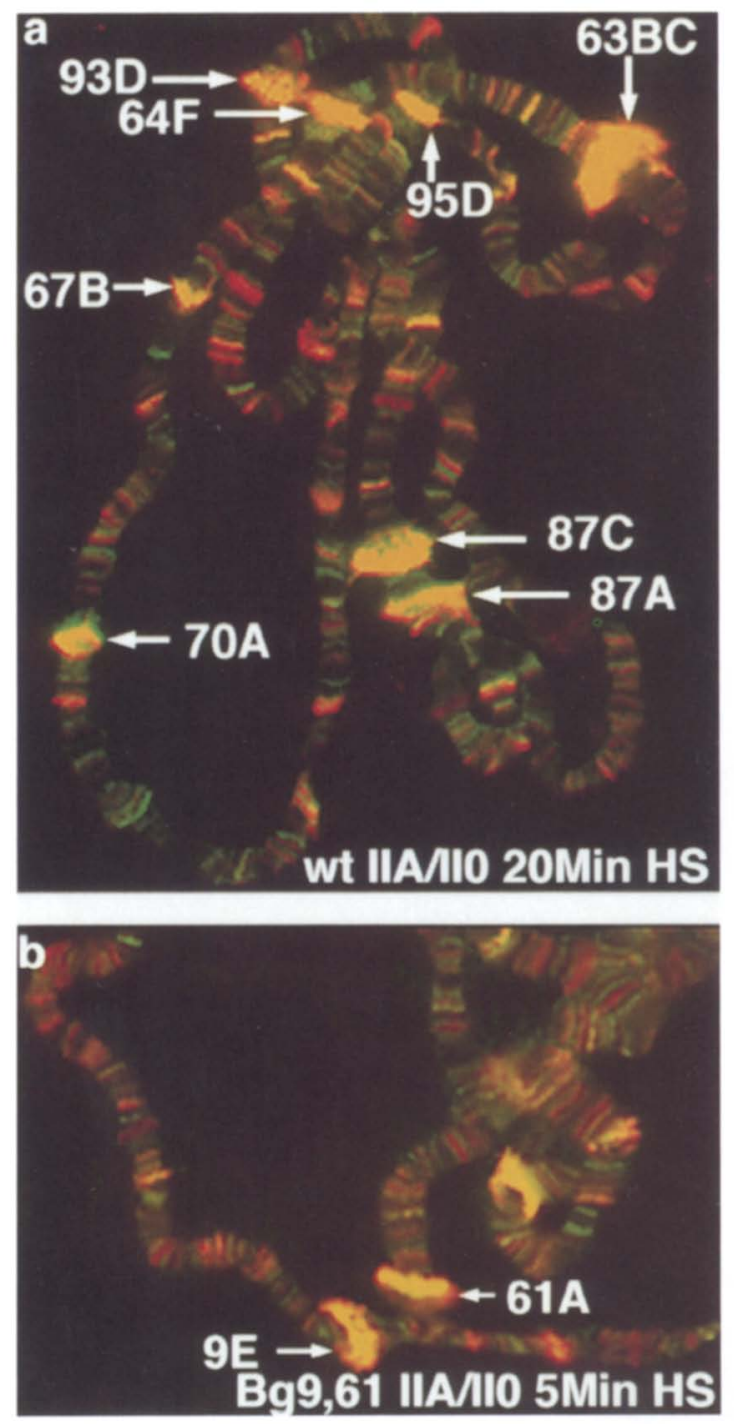

Figure 5. RNA Pol IIA and Pol IIO on heat shock puffs. (a) A chromosome preparation from a wild-type larva heat-shocked for $\sim 20$ min at $37^{\circ} \mathrm{C}$ was reacted with goat anti-IIA (green) and rabbit anti-IIO (red) antibodies; overlay shown. Major heat shock puffs are labeled. (b) Goat anti-IIA (green) and rabbit anti-IIO (red) staining of chromosomes from transformant $\mathrm{Bg} 9,61$ larva heat-shocked for $\sim 5 \mathrm{~min}$ at $37^{\circ} \mathrm{C}$; overlay image. Puffs at insertion sites near $9 \mathrm{E}$ and $61 \mathrm{~A}$ are indicated.

forms of the enzyme. Similar color and uniformity of staining are observed consistently on puffs induced for times ranging from $\sim 4-20 \mathrm{~min}$.

In addition to the endogenous heat shock puffs, most of which contain several clustered heat shock genes, we monitored two novel puffs that form at the insertion sites of a previously characterized hybrid transgene consisting of a single $h s p 70$ promoter and $5^{\prime}$ portion of the hsp70 gene linked to $l a c Z$ (Lis et al. 1983; Simon et al. 1985). We used the $\mathrm{Bg} 9,61$ transformant strain that carries this transgene inserted at two separate sites: in polytene band regions $9 \mathrm{E}$ and $61 \mathrm{~A}$. We hoped that these transgene puffs would simplify interpretation because heat shock-induced transcription begins at a single site and proceeds unidirectionally to cause a fairly large puff. Figure $5 \mathrm{~b}$ shows that after $\sim 5 \mathrm{~min}$ of heat shock, the transgene puffs at $9 \mathrm{E}$ and $61 \mathrm{~A}$ stain in a pattern resembling that of the endogenous heat shock puffs, that is, they stain strongly for both IIA and IIO, giving a uniformly yellow-orange color. Longer heat shocks result in much larger puffs that continue to stain strongly with both antibodies (not shown). Note that this transgene construct produces a stable transcript of $\sim 11 \mathrm{~kb}$ and even longer readthrough products (Simon et al. 1985). These transcripts are many times longer than the endogenous heat shock gene transcripts, a fact that might explain the large size of the transgene puffs.

\section{Pol IIA at the hsp70-lacZ transgene insertion site before induction}

Previous experiments had discovered a Pol II molecule arrested at the $5^{\prime}$ end of the uninduced hsp 70 transcription unit (Gilmour and Lis 1986), apparently having initiated an RNA chain but having stopped after polymerizing 25 nucleotides (Rougvie and Lis 1988; Giardina et al. 1992). Like the endogeneous loci, the hsp70-lacZ transgene construct in transformant $\mathrm{Bg} 9,61$ had also been shown to carry a $5^{\prime}$-arrested Pol II (Lee et al. 1992); therefore, we attempted to observe Pol II on the hybrid transgene before heat shock.

Figure 6 shows that in non-heat-shocked samples we do observe in the transformant strain distinct Pol IIA signals at the $9 \mathrm{E}$ and $61 \mathrm{~A}$ insertion sites that are not present in wild type. For reference, Figure 6 , a and $a^{\prime}$, show the banding patterns around the insertions sites; several prominent bands are labeled. Figure $6, \mathrm{~b}$ and $\mathrm{b}^{\prime}$, shows wild-type chromosomes stained with anti-IIA (green) and anti-IIO (red). Transformant Bg9,61 chromosomes stained with anti-IIA and anti-IIO are shown in Figure 6, $\mathrm{c}$ and $\mathrm{c}^{\prime}$. Comparing Figure 6, b with $\mathrm{c}$ and $\mathrm{b}^{\prime}$ with $\mathrm{c}^{\prime}$, reveals transposon-dependent green (IIA) fluorescence signals at the two insertion sites; these are indicated by arrows labeled $9 \mathrm{E}$ and $\mathrm{t}$ in $\mathrm{c}$ and $\mathrm{c}^{\prime}$, respectively. We also observe a Pol IIA-only signal at sites of endogenous heat shock genes in unshocked preparations (not shown), although negative controls for these observations are not conveniently available.

Previously, other work had also described the presence of bound protein on the TATA box before heat shock induction (Wu 1984; Giardina et al. 1992), and recent in situ localizations similar to those described here also have detected TATA-binding protein (TBP) at the 87A and $87 \mathrm{C}$ sites of endogenous $h s p 70$ genes on unshocked polytene chromosomes (Carl $\mathrm{Wu}$, pers. comm.). Using antibodies to the TBP component of TFIID, we also observe a strong transgene-specific signal that colocalizes with the novel Pol IIA signal in unshocked preparations (not shown).

One interpretation of our results is that Pol II arrested on the $5^{\prime}$ end of $h s p 70$ genes is form IIA; this interpretation is consistent with results of recent UV cross-link- 

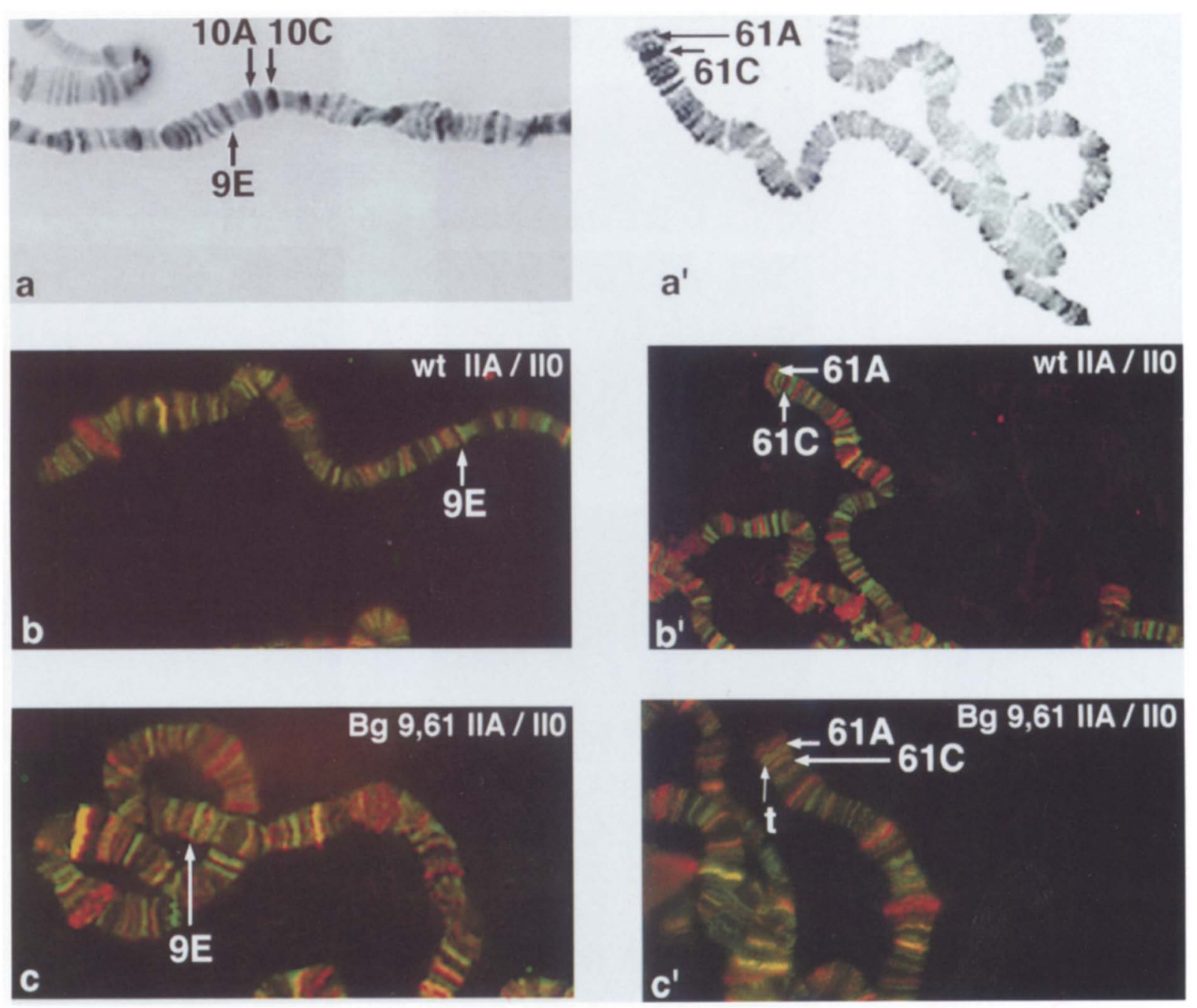

Figure 6. Staining patterns at $h s p 70-1 a c Z$ transgene sites without heat shock. $\left(a, a^{\prime}\right)$ DAPI-stained sections of chromosomes showing regions around transposon insertion sites near $9 \mathrm{E}$ and $61 \mathrm{~A}$; images reversed to mimic classical banding pattern (most intense fluorescence appears darkest). Several prominent bands are indicated. $\left(b, b^{\prime}\right)$ Goat anti-IIA (green) and rabbit anti-II0 (red) staining of non-heat-shock wild-type preparations; overlay images. (c, $\left.c^{\prime}\right)$ Goat anti-IIA (green) and rabbit anti-II0 (red) staining of non-heat-shock transformant $\mathrm{Bg} 9,61$ preparations; overlay images. In $c$, the arrow labeled $9 \mathrm{E}$ points at a novel fluorescence signal present in transformant chromosomes. In $c^{\prime}$, the arrow labeled $t$ points at a novel fluorescence signal present in transformant chromosomes.

ing experiments that show the arrested enzyme to be Pol IIA (T. O'Brien, S. Hardin, A.L. Greenleaf and J.T. Lis, in prep.). Because the transposon also contains a partial $\mathrm{P}$ element and the rosy gene (Lis et al. 1983), however, it is possible that Pol II or TBP bound to either P or rosy sequences in the transposon could contribute to the signals that we observe in non-heat-shocked samples. It will be feasible to test this possibility formally in the future by using transgene constructs with altered $h s p 70$ promoter regions (e.g., Lee et al. 1992); meanwhile, experiments with heat-shocked chromosomes, presented in the next section, already provide support for the first interpretation.

\section{Pol IIA and heat shock factor on induced hsp70-lacZ transgene puffs}

Because heat shock induction of $h s p 70$ depends on bind- ing of the heat shock factor (HSF) to the regulatory elements (HSEs) in the hsp70 promoter (e.g., Westwood et al. 1991, and references therein), we checked for the presence of HSF at the transgene sites after short heat shocks. First, controls with wild-type chromosomes confirmed that HSF (and Pol IIA) was not present at the transposon insertion sites in the absence of the transposon (Fig. 7a, $\mathrm{a}^{\prime}$ ). In contrast, strong HSF (red) and Pol IIA (green) signals appeared at both insertion sites in transformant $\mathrm{Bg} 9,61$ chromosomes (Fig. $7 \mathrm{~b}, \mathrm{~b}^{\prime}$ ), with the overlap of the red and green signals producing novel orangish bands labeled 9E and $t$ in $b$ and $b^{\prime}$, respectively. At this short induction time $(90 \mathrm{sec})$, no noticeable puffs had formed. Note that in control experiments (not shown) with transformant $B g 9,61$ without heat shock, we observed no HSF signal at the insertion sites [consistent with expectations based on the results of Westwood et al. (1991).] 
Weeks et al.
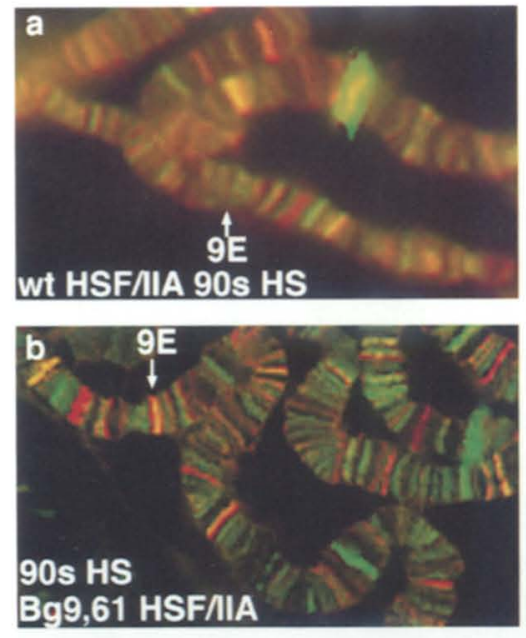

Figure 7. Pol IIA and heat shock factor at hsp70-lacZ transgene sites after heat shock. Rabbit anti-HSF (red) and goat antiIIA (green) staining of chromosomes from wild-type and transformant $\mathrm{Bg} 9,61$ salivary glands. $\left(a, a^{\prime}\right)$ Wild-type salivary glands heat-shocked in $37^{\circ} \mathrm{C}$ buffer for $\sim 90$ sec. Arrows labeled $9 \mathrm{E}$ and $\mathrm{t}$ point at sites in regions $9 \mathrm{E}$ and $61 \mathrm{~A}$, respectively, that lack fluorescence signals. $\left(b, b^{\prime}\right)$ Transformant $\mathrm{Bg} 9,61$ salivary glands heat-shocked in $37^{\circ} \mathrm{C}$ buffer for $\sim 90 \mathrm{sec}$. Arrows labeled $9 \mathrm{E}$ and $\mathrm{t}$ point at sites of transposon-dependent fluorescence signals in regions $9 \mathrm{E}$ and $61 \mathrm{~A}$, respectively. $\left(c, c^{\prime}\right)$ Transformant larva heat-shocked for $5 \mathrm{~min}$; chromosomes stained with goat anti-IIA. Arrows $9 \mathrm{E}$ and $\mathrm{t}$ indicate point at more intense signals near one edge of the induced transgene-dependent heat shock puffs in regions $9 \mathrm{E}$ and $61 \mathrm{~A}$, respectively. $\left(d, d^{\prime}\right)$ Same preparations as in $c$ and $c^{\prime}$, stained with rabbit anti-HSF; arrows as in $c, c^{\prime} . \mid e$, $\left.e^{\prime}\right)$ Overlay of images in $c$ and $d$ and $c^{\prime}$ and $d^{\prime}$, respectively. Bar in $e, 5 \mu \mathrm{m}$.
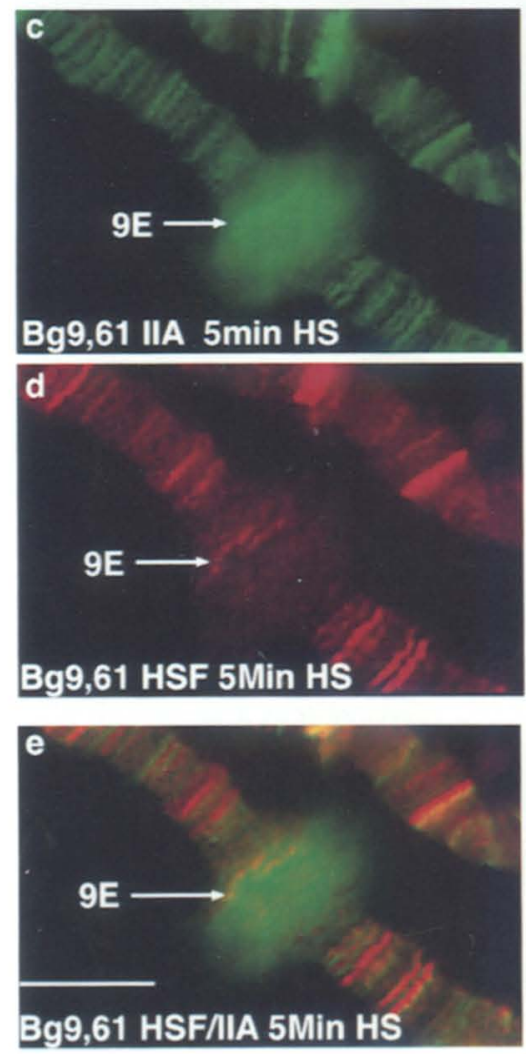
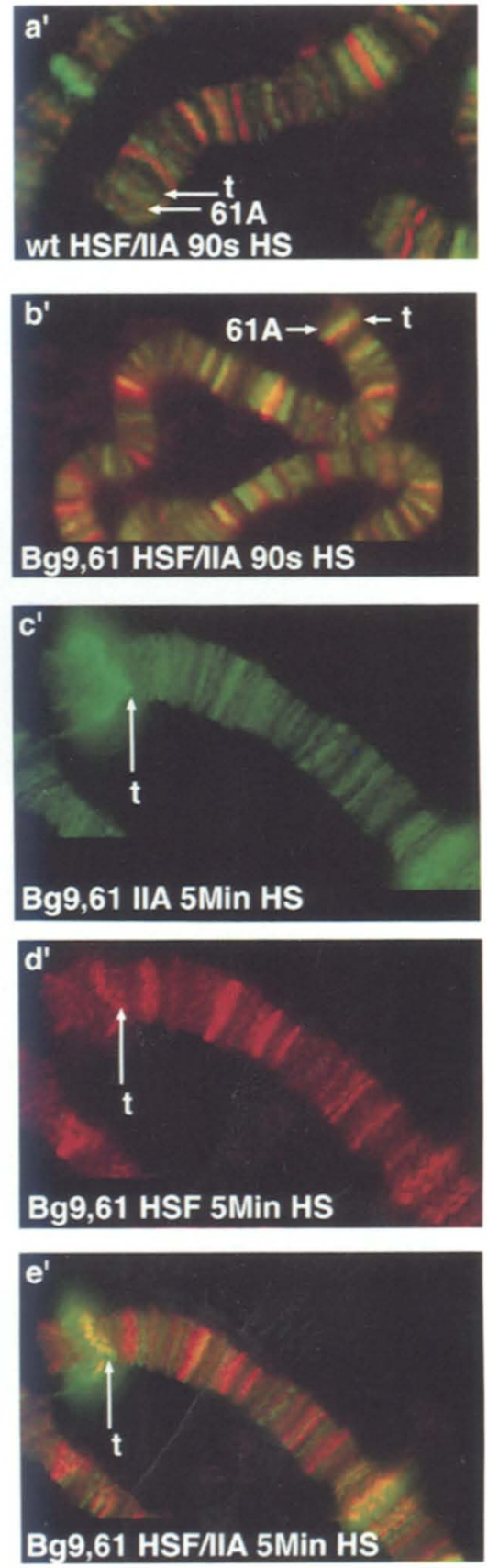

We then investigated the HSF and Pol II distributions in transgene-dependent puffs induced by slightly longer heat shocks; the results are shown in the remaining panels of Figure 7. A 5-min shock is clearly sufficient to induce substantial transgene-dependent puffing at both insertion sites, and the entirety of each puff labels strongly with anti-IIA as anticipated (Fig. $\left.7 c, c^{\prime}\right)$. Note that in each case one edge of the puff displays a stripe of more intense fluorescence, as indicated by the arrows labeled $9 \mathrm{E}$ and $\mathrm{t}$. Staining the same preparations with anti-HSF (Fig. 7 d, d') reveals a much more restricted distribution than for Pol II, with the HSF concentrated in each case at one edge of the puff. The overlay images in Figure 7, e and $\mathrm{e}^{\prime}$, reveal that the HSF signal appears to superimpose over the more intense stripe of the Pol IIA signal, generating an orange stripe near one edge of each puff (arrows labeled 9E and $t$ ). One interpretation of these results is that the HSF signal emanates from HSF molecules clustered at the promoter region of the transgene, whereas the Pol II signal emanates both from enzyme molecules present at high density near the $5^{\prime}$ end of the gene and from Pol II molecules distributed at somewhat lower density along the heat shock-inducible transcription unit out to the $3^{\prime}$-most point reached by poly- 
merases during the 5-min induction [note that the transcription unit is $\geqslant 11 \mathrm{~kb}$ long (Simon et al. 1985)]. This interpretation is consistent both with the known orientation of the transposon at each insertion site (Simon et al. 1985) and with a pause at the arrest site being rate limiting even for $37^{\circ} \mathrm{C}$ heat shocks (Giardina et al. 1992).

\section{HnRNP proteins colocalize primarily with Pol IIO}

To explore further the relationship between transcriptional activity and CTD phosphorylation state under non-heat-shock conditions, we double-labeled chromosomes with anti-IIO or anti-IIA and with antibodies that we assumed would label most nascent transcriptsmonoclonal antibodies to hrp36 and hrp48, two major Drosophila hnRNP proteins (Matunis et al. 1992). The results shown in Figure $8 \mathrm{a}$ are typical; many sites of $\mathrm{IIO}$ staining (green) also stain for hrp proteins (red), such that
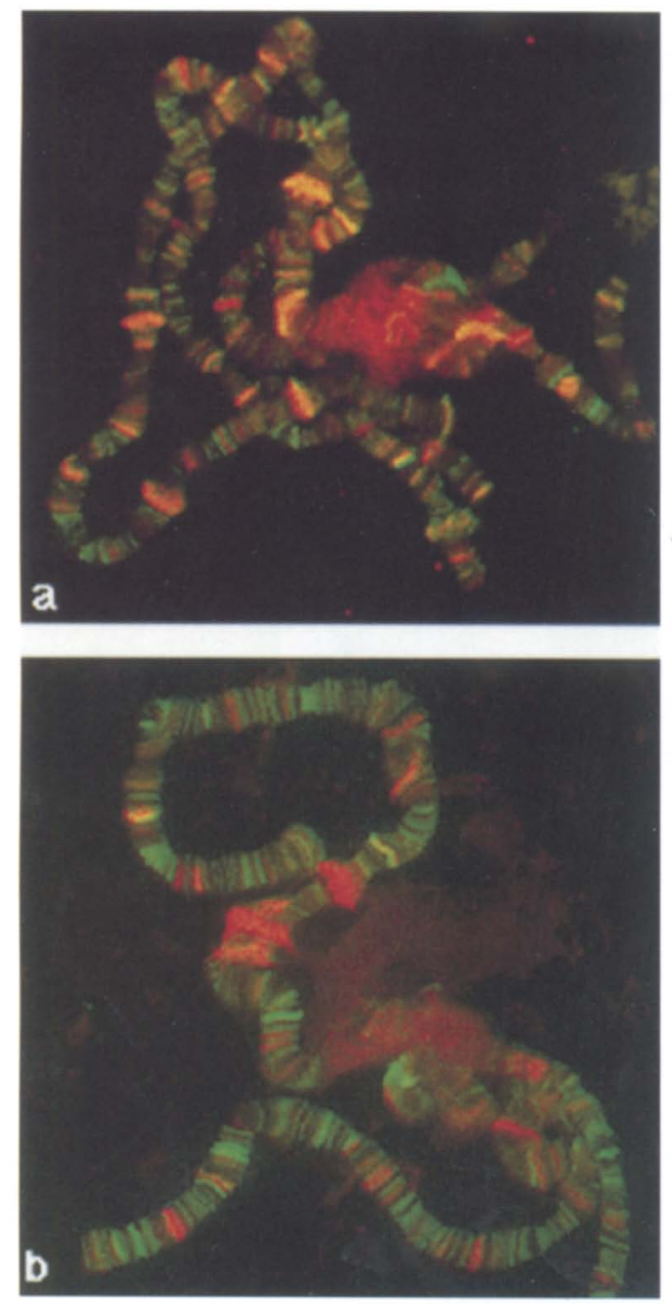

Figure 8. HnRNP proteins preferentially colocalize with Pol II0. Non-heat-shock preparations were double labeled with mouse monoclonal antibodies to Drosophila hrp36+hrp48 (red) and either rabbit anti-IIO (green) (a) or goat anti-IIA (green) (b); overlay images. in the overlay image these sites are some shade of orange. Most developmental puffs stain consistently for both IIO and hrp proteins. These results thus support the idea that IIO is transcriptionally active at developmental puffs and potentially at many additional sites. Note that the staining of the chromocenter seen here is apparently a property shared by a number of anti-heterogenous nuclear ribonucleoprotein (anti-hnRNP) antibodies (S. Haynes, pers. comm.).

Unexpectedly, a number of sites that contain IIO do not stain for hrp proteins (Fig. 8a, green sites), a result that might suggest IIO at these loci is not active. Another interpretation, however, is suggested by recent studies of several Drosophila hrp proteins, as it now appears that active loci are not stained equally by all anti-hrp antibodies (G. Dreyfuss and E. Matunis, pers. comm.). Thus, the green sites in Figure 8a (IIO only) may represent active sites whose nascent transcripts simply contain little or no hrp36 and hrp48. We obtained very similar results with a monoclonal antibody against hrp40.

Further inspection of Figure $8 \mathrm{a}$ and other similar preparations indicates that there are a few sites that seem to stain for hrp proteins but not for IIO (i.e., red only). Conceivably, this type of site might represent a locus being transcribed by IIA.

We also compared directly the distributions of hrp36+ hrp48 (red) and RNA polymerase IIA (green), as shown in Figure $8 \mathrm{~b}$. As anticipated from the above results, we found that many sites of hrp staining (especially puffs) did not stain for IIA and many sites of IIA staining (green) did not stain for hrp. On the other hand, a few sites did stain for both IIA and hrp. Although this latter result could suggest that IIA is active at these sites, it is possible that such sites also contain IIO (as in previous Figures) and that IIO is generating the nascent transcript. This experiment cannot distinguish between these possibilities.

To see whether we could identify a IIA-only site that was transcriptionally active, we first reacted chromosomes with anti-IIA + anti-IIO as usual and identified sites with only IIA present (green). We then restained the same preparation with a mixture of monoclonal antibodies to hrp40, hrp36, and hrp48, followed by a red secondary antibody. If a IIA site carried a nascent transcript complexed with hrp proteins, it should now fluoresce an orange color. A limited attempt that scanned approximately one-half of the $\mathrm{X}$ chromosome failed to reveal such a site (not shown).

\section{RNA Pol IIO colocalizes with a splicing component}

Splicing in Drosophila has been shown to occur cotranscriptionally (Beyer and Osheim 1988; Lemaire and Thummel 1990; see also Gall 1991; Greenleaf 1993 and references therein; Jimenez-Garcia and Spector 1993; Xing et al. 1993); we therefore wondered how the distribution of a splicing component might compare with that of RNA Pol II0 or Pol IIA. Figure 9a shows chromosomes stained for the U1 $70 \mathrm{~K}$ small nuclear ribonucleoprotein (snRNP) (red) and Pol II0 (green). The major result is that 

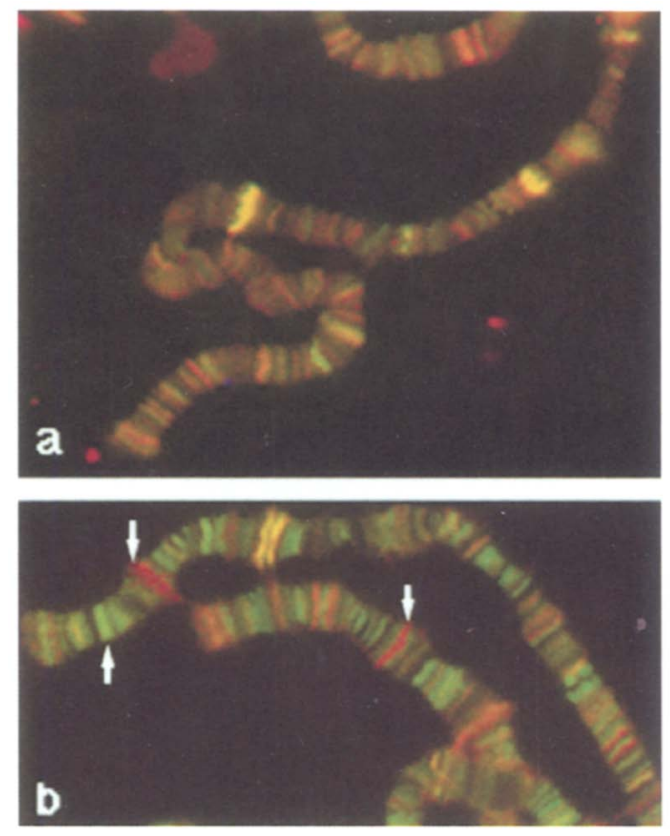

Figure 9. A splicing component preferentially colocalizes with Pol II0. Non-heat-shock preparations were double labeled with a mouse monoclonal antibody to Ul snRNP $70 \mathrm{~K}$ protein (red) and either rabbit anti-IIO (green) ( $a$ ) or goat anti-IIA (green) (b). In $b$, examples of red signals (downward arrows) and a green signal (upward arrow) are indicated; overlay images.

most sites containing IIO also contain U1 70K /yellow or orange) and that few $70 \mathrm{~K}$ sites lack IIO (they would be red). In contrast, Figure $9 \mathrm{~b}$ shows that there is much less correlation between the Pol IIA and U1 70K patterns (e.g., there are numerous red, $\mathrm{U} 170 \mathrm{~K}$-only, sites and numerous green, IIA-only, sites); furthermore, the presence of U1 $70 \mathrm{~K}$ at IIA sites might be explained by the presence of IIO at those sites.

\section{RNA polymerase is in interbands and puffs}

Previous studies using an anti-RNA Pol II serum (Jamrich et al. 1977) indicated that the enzyme was located primarily in puffs and interbands, rather than in the bands that are more condensed and contain most of the DNA mass. To relate our current work to earlier experiments, we compared the anti-IIA and anti-IIO signals with a signal from DAPI, a fluorescent dye that binds to DNA and produces a pattern nearly identical to the classical banding pattern (e.g., see Fig. 6a). Both the IIA and IIO patterns are largely nonoverlapping with the DAPI pattern (not shown; also see Fig. 6), indicating again that the polymerases that we detected are predominantly in the least condensed regions of the polytene chromosomes, the puffs and interbands.

\section{Discussion}

We have visualized the in vivo distributions of differentially phosphorylated forms of RNA Pol II on Drosophila polytene chromosomes, using antibodies sensitive to the phosphorylation state of the CTD of the Pol II largest subunit. We find RNA Pol IIA and Pol II0, with hypoand hyperphosphorylated CTDs, respectively, arrayed in markedly different, locus- and condition-specific patterns representing three classes of sites. One class contains only Pol IIO, another class contains only Pol IIA, and the third class contains a mixture of Pol IIA and Pol IIO. To begin to understand these patterns, we have established correlations between the nature and activity of certain loci and the phosphorylation state of Pol II there, and we have monitored the colocalization of RNA Pol IIA and Pol IIO with other nuclear proteins involved in either transcriptional regulation or pre-mRNA metabolism.

One primary result is that the large developmental puffs, reflecting gene activity at loci induced by the molting hormone ecdysone, contain predominantly Pol IIO. Because the anti-IIO antibodies react only with the hyperphosphorylated CTD, and because the largest puffs are virtually unstained by anti-IIA antibodies that react with the hypophosphorylated CTD, we conclude that the polymerases present on the body of these puffs are essentially only the hyperphosphorylated form. Furthermore, we suggest that these enzymes are actively elongating RNA chains. First, experiments that detect both hnRNP proteins and Pol IIO on the same puffs support the contention that we are observing active enzymes, those that were generating nascent transcripts at the moment of sample preparation. Second, the two major early puffs at 74EF and 75B exhibit a spatially uniform staining pattern, suggesting that we are observing enzyme molecules distributed along the entire length of these large, 50- to 60-kb transcription units (Burtis et al. 1990; Segraves and Hogness 1990; Thummel et al. 1990). Thus, in the case of the major ecdysone puffs, our in vivo observations are consistent with the idea that the elongating form of the enzyme is II0 /see introductory section and Fig. 10a).

Another clear result is that the Pol II molecules transcribing the heat shock loci differ in phosphorylation state from those transcribing the major developmental puffs. Heat shock puffs induced at $37^{\circ} \mathrm{C}$ stain strongly with both anti-IIO and anti-IIA antibodies. Because the anti-IIA antibodies do react with incompletely phosphorylated CTD (Fig. 2), we cannot tell whether the antiIIA-reactive polymerases on heat shock puffs are completely unphosphorylated, partially phosphorylated, or a mixture of both. We can conclude, however, that a substantial fraction of the enzyme on these puffs is not fully phosphorylated.

Because heat shock genes are much shorter than, for example, the ecdysone-induced genes at 74EF and 75B, the ratio of promoter/initiation region to gene body is much higher for the heat shock genes. If a different form of Pol II were present on the promoter/initiation region than on the body of the gene, one could argue that the staining we see is a superposition of signals from one form of Pol II at or near the promoter [e.g., the arrested Pol II described by Lis and colleagues /Gilmour and Lis 


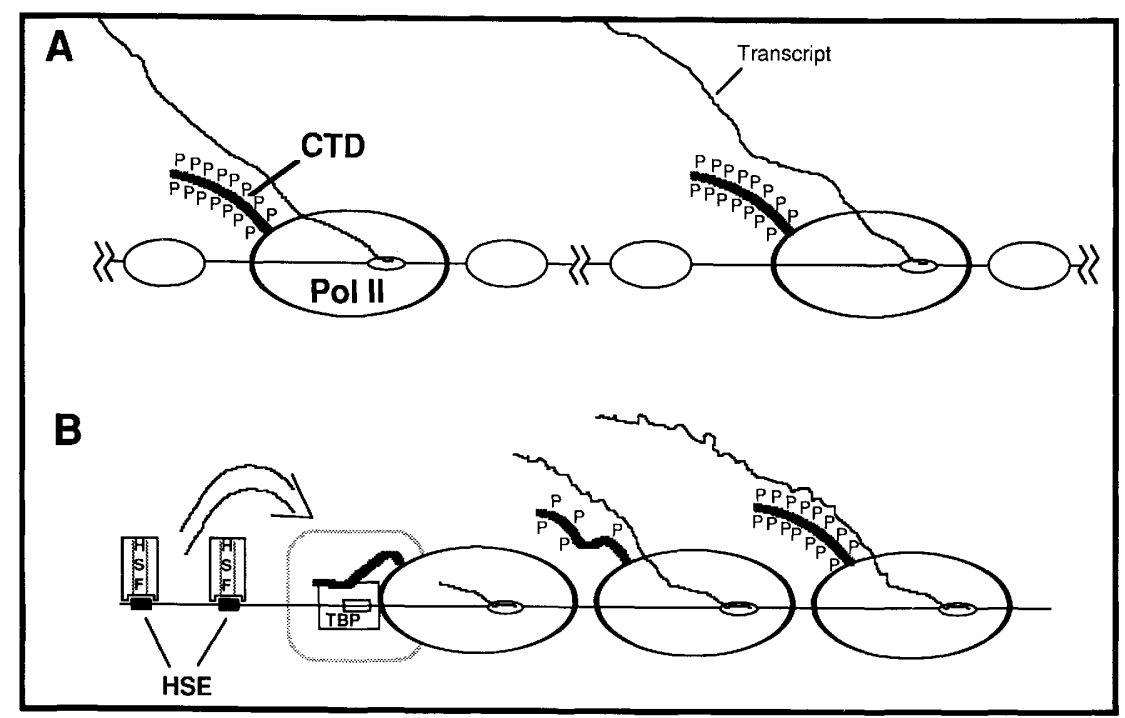

Figure 10. Model of Pol II transcribing two different kinds of gene. $(A)$ A gene transcribed by Pol II0. A long ecdysoneinduced gene, such as $E 74 A$, is transcribed only by polymerases with fully phosphorylated CTDs. Polymerase density is not actually known, but it is envisioned as being less than maximal, such that nucleosomes (smaller ovals) could reform between passage of polymerse molecules. HnRNP proteins and splicing components are not shown (see text). (B) Transcription of a heat shock gene. Actively elongating polymerases are either hyper- or hypophosphorylated, as indicated by many or few P's on the CTD (note, an incompletely phosphorylated CTD would stain as IIA; see text). Polymerase density on induced heat shock genes at $37^{\circ} \mathrm{C}$ is very high, as represented by enzyme molecules almost touching. TBP component of TFIID is shown bound to the TATA box (rectangle within TBP). Other components of TFIID presumably present, and additional factors that may be bound at the promoter, are represented by the larger, stippled square surrounding TBP. Activated HSF trimers (Rabindran et al. 1993) are bound to the HSEs [there are actually three in the $194 \mathrm{bp}$ of upstream sequence present in the $h s p 70-1 a c Z$ transgene construct (Xiao and Lis 1988)] and activate transcription of the gene (unknown mechanism indicated by open curved arrow). Presumed arrested Pol II is depicted with its $\sim 25$ nucleotide nascent transcript eminating from the transcription bubble and with its unphosphorylated CTD (see Fig. 6; Discussion) contacting components of TFID (see introductory section).

1986; Rougvie and Lis 1988)] and another form on the gene body. We think that this is unlikely for several reasons. First, the density of polymerases on an induced hsp70 gene is very high, $\sim 30-40$ enzymes/2.4-kb transcription unit, or $\sim 1$ enzyme/60-80 bp (O'Brien and Lis 1991). Thus one $5^{\prime}$-arrested Pol II would represent only $\sim 1 / 40-1 / 30$ of the total Pol II signal for an $h s p 70$ gene. The staining that we observe does not seem consistent with this ratio. Furthermore, the nearly uniform anti-IIA and anti-IIO staining that we observe for a heat shock-induced transgene that contains only one heat shock promoter and a longer than normal transcription unit is virtually indistinguishable from that for the endogenous heat shock puffs, which contain several promoters and short transcription units. We suggest that these observations are consistent with the proposal that the actively elongating polymerases on heat shock genes are a mixture of hyperphosphorylated enzyme ( $\mathrm{Pol} \mathrm{IIO}$ ) and hypoor nonphosphorylated enzyme (Pol IIA?).

We generated additional information relevant to interpreting the immunofluorescence images by using the transgene-dependent heat shock puffs to compare the spatial distribution of a regulatory transcription factor, HSF, with that of Pol II. In favorable preparations le.g., Fig. 7c-e) we visualized distinct patterns for HSF and Pol II, suggesting that we can resolve signals resulting from proteins bound at or near the promoter from signals resulting from proteins bound at more 3 ' positions along the hsp70-lacZ transcription unit. The following considerations argue that this resolution should be feasible. This artificial transcription unit is $\geqslant 11 \mathrm{~kb}$ long (Simon et al. 1985), and after a 5-min heat shock Pol II molecules should have traveled nearly to its end, if we assume that the elongation rate for Drosophila $\mathrm{Pol}$ II at $37^{\circ} \mathrm{C}$ is $\sim 2$ $\mathrm{kb} / \mathrm{min}$ and that there is little lag in beginning elongation after temperature shift. Furthermore, the induced puff at the 9E insertion site in Fig. 7c-e is 3-4 $\mu \mathrm{m}$ long, which at a minimum would represent 9-12 kb of DNA, a length consistent with the distance Pol II molecules could have traversed in $5 \mathrm{~min}$. Thus, the anti-Pol II staining of the body of the puff may correlate directly with the spatial distribution of polymerases arrayed along the hsp70-lacZ transcription unit, and the localized antiHSF and anti-Pol II staining near one edge of the puff may correlate directly with promoter-proximal concentrations of the two proteins. Future work will test the validity of these interpretations, but the results already obtained hint that using in situ immunolocalization to study further this and other transgene constructs will be valuable in helping to fashion a better understanding of in vivo regulatory events by providing a detailed description of components present at particular chromosomal sites both before and after induction.

The experiments that we have presented suggest a picture of transcription for two different classes of gene as depicted in Figure 10. The long ecdysone-induced genes, such as those at $74 \mathrm{EF}$ and $75 \mathrm{~B}$, are transcribed by very highly (completely?) phosphorylated Pol IIO (Fig. 10A). In contrast, polymerases actively elongating transcripts on heat shock genes carry, on average, fewer phosphates (Fig. 10B). [The properties of the anti-IIA and anti-IIO antibodies do not enable us to distinguish between two possibilities at present: (1) a homogeneous population of highly but not completely phosphorylated enzymes; or (2) a mixed population of highly phosphorylated, and non or slightly phosphorylated enzymes, as depicted in Fig. 
10B]. Furthermore, our results with the uninduced $h s p 70$ lacZ transgene are consistent with those of $\mathrm{O}^{\prime}$ Brien, $\mathrm{S}$. Hardin, A.L. Greenleaf, and J.T. Lis, (in prep.), which indicate that arrested Pol II, which has synthesized an RNA chain of $\sim 25$ nucleotides, is form IIA. For heat shock promoters, then, the initiation of RNA synthesis seems to be uncoupled from CTD phosphorylation. The transcriptional event correlated with CTD phosphorylation would then appear to be the HSF-mediated release of the arrested Pol IIA and/or the transit of the elongating polymerases through the body of the gene.

Like the easily identifiable and well-characterized heat shock genes, many currently anonymous sites also stain with both anti-IIA and anti-IIO antibodies. Whether this characteristic indicates any underlying similarity to the heat shock loci is not clear. It seems likely that the subclass of these sites with a high IIO/IIA ratio is transcriptionally active, in view of the general correspondence between staining for IIO and staining for hrp proteins, presumed markers of nascent transcripts; some of these sites stain for both IIA and hrp proteins. The activity status of most sites with a low IIO/IIA ratio is currently unknown.

Sites that stain exclusively for IIA appear to equal or outnumber those that stain exclusively for IIO. The majority of these IIA-only sites apparently lack nascent RNAs, as they do not stain for hrp proteins. We made a very limited attempt to find a IIA-only site that also stained for hrp protein but were unsuccessful. Thus, we have no direct evidence that the IIA at any of these locations is engaged in elongating RNA chains. We suggest that at least some of the IIA-only sites represent nonheat-shock loci with an arrested Pol IIA; a number of Drosophila genes with an arrested Pol II have been identified previously by other approaches (Rougvie and Lis 1990; Giardina et al. 1992) and may represent a subset of the sites that we observe. Other IIA-only sites might represent stationary polymerases that are parked, stored, or sequestered at specific locations. And finally, because unrecognized technical problems might have frustrated our attempts to find an active IIA, it remains possible that some IIA-only sites contain actively elongating RNA polymerases.

We have not addressed directly the question, "What is the role of the phosphorylated CTD, given the apparent correlation between phosphorylation and RNA chain elongation?" Among previously suggested roles (e.g., Corden 1990), two seem consistent with our finding that the long, alternatively spliced ecdysone-induced genes with multiple introns are transcribed by more highly phosphorylated Pol II than the shorter, intronless hsp70 genes. The fully phosphorylated CTD is an example of an acidic polymer that may serve to catalyze the displacement of histone $\mathrm{H} 2 \mathrm{~A} / \mathrm{H} 2 \mathrm{~B}$ dimers from nucleosomes to facilitate the passage of Pol II /Hansen and Ausio 1992). This function might be less critical on (often short) genes with very high polymerase densities (e.g., heat shock genes) than on long genes with presumably lower polymerase densities (e.g., E74 and E75). In the former case, nucleosomes have no chance to reform after passage of one Pol II molecule because the next one follows too closely (as in Fig. 10B). In the latter case, each Pol II must make its way through the nucleosome barriers independently (Fig. 10A). In this scenario it is not critical to elongation efficiency that polymerases transcribing the heat shock genes be hyperphosphorylated, whereas it is essential that polymerases transcribing long ecdysone-inducible genes be fully phosphorylated.

Another proposed role for the PCTD is to serve as a docking and deployment site for certain splicing components and regulators, those with positively charged domains postulated to interact with the negatively charged PCTD (Greenleaf 1993; see also Corden 1990). Our results showing a relatively good correlation between Pol IIO and U1 snRNP 70K protein and a relatively poor correlation between Pol IIA and U1 70K are consistent with this idea, as are the results just discussed that associate IIO with long, multiple intron-containing genes (whose pre-mRNAs are subject to alternative splicing). On the other hand, these correlations do not provide decisive support for this idea because Pol IIO appears to correlate in general with transcriptional activity and would therefore also correlate with splicing activity. More critical tests of the idea might, however, result from the identification of other specific loci transcribed by IIA or IIA/ IIO, especially if such loci tended to be intronless or not alternatively spliced.

The model in Figure 10 can also serve to highlight several features of CTD phosphorylation that we do not understand. The following questions cover a partial list of those features. Do the ecdysone-induced genes also have an arrested Pol II before induction and, if so, is it form IIA? Does CTD phosphorylation cause or is it a consequence of the release of 5 '-arrested Pol IIA? For heat shock genes, is each Pol II that commences elongation phosphorylated to the same extent or does the extent of phosphorylation change with induction time or temperature? How does the binding of HSF mediate the release of arrested Pol IIA and the phosphorylation of its CTD? What is the identity of the CTD kinase that phosphorylates the arrested Pol IIA, and does the same kinase act on subsequently initiating polymerases? Is the CTD kinase acting at heat shock promoters the same as that acting at other promoters, such as those for the major developmental puff genes?

Besides helping to answer questions about the physiology of CTD phosphorylation, the approach described in this paper should offer enough sensitivity and resolution to provide new insights into the in vivo properties and behavior of other components of the eukaryotic transcription apparatus and the RNA processing machinery.

\section{Materials and methods}

\section{Antibodies}

Goat antibodies directed against the second exon of RNA Pol II largest subunit (anti-exon2 IgGs) were affinity purified on a column carrying a LacZ-exon 2 fusion protein as described (Lee and Greenleaf 1991, therein referred to as anti-DmE2). Goat anti-CTD antibodies (anti-IIA) were affinity purified (Robbins et 
al. 1984) from the same serum using a column carrying a LacZDrosophila CTD fusion protein (Lee and Greenleaf 1989, therein referred to as D-FP). To prepare rabbit anti-phosphoCTD antibodies (anti-IIO), $100 \mu \mathrm{g}$ of D-FP was hyperphosphorylated with yeast CTD kinase (Lee and Greenleaf 1989), and this PCTD fusion protein was injected into a rabbit. Four weeks later, the rabbit was boosted with a similar amount of PCTD fusion protein, and blood was collected beginning 2 weeks later. Total rabbit IgGs were then purified using a protein-A column and passed through a CTD fusion protein column; from the flowthrough anti-PCTD, IgGs were affinity purified using a column carrying a hyperphosphorylated glutathionine $S$-transferase (GST)-CTD fusion protein.

A monoclonal antibody to U1 snRNP 70-kD protein (U1 70K) was purified from a culture supernatant, a generous gift from $\mathrm{S}$. Pelsue and P. Agris (North Carolina State University, Raleigh) [the cell line used was line 2.73 from S. Hoch (Billings et al. 1982; Pelsue et al. 1993/]. Ammonium sulfate precipitation and protein A affinity chromatography yielded $\sim 200 \mu \mathrm{g}$ of $\mathrm{IgG}$ from $500 \mathrm{ml}$ of supernatant.

Rabbit anti-HSF was a generous gift from Carl Wu (National Cancer Institute, Bethesda, MD) Monoclonal antibodies to Drosophila hnRNP proteins were a generous gift from E. Matunis and G. Dreyfuss (University of Pennsylvania Medical School). The anti-hrp40, -hrp36, and -hrp48 antibodies were monoclonals 8D2, 5A5, and 10D5, respectively (Matunis et al. 1992). Rabbit anti-TBP was a generous gift from C. Tyree and J. Kadonaga (University of California, San Diego).

Secondary antibodies for Western blots were from Boehringer Mannheim. Secondary antibodies for immunofluorescence microscopy were affinity-purified donkey IgGs (ML grade) labeled with fluorescein, rhodamine, or Texas red, from Jackson ImmunoResearch Labs, Inc. The Jackson secondary antibodies gave very little nonspecific background or cross-species reactivity.

\section{Quickly prepared Drosophila embryo extracts}

Wild-type embryos were collected overnight, washed thoroughly on a nitrex filter with $0.5 \% \mathrm{NaCl} / 0.1 \%$ Triton $\mathrm{X}-100$, dechorionated in $3 \%$ Clorox solution for $2 \mathrm{~min}$, rinsed several times with $0.5 \% \mathrm{NaCl} / 0.1 \%$ Triton $\mathrm{X}-100$, and finally rinsed with deionized $\mathrm{H}_{2} \mathrm{O}$. The embryos were weighed, suspended in cold $\left(-20^{\circ} \mathrm{C}\right) 95 \%$ ethanol containing phenylmethylsulfonyl fluoride ( $1 \%$ of a saturated solution in isopropanol), and homogenized in a small glass homogenizer (e.g., Radnoti econo-grind homogenizer, Fisher Scientific 08-416C) on dry ice. After centrifugation of the homogenate at $5000 \mathrm{rpm}$ and $0^{\circ} \mathrm{C}$ for $5 \mathrm{~min}$, the pellets were dried briefly under vacuum and suspended in hot $\left(\sim 95^{\circ} \mathrm{C}\right)$ SDS sample buffer (50 mM Tris- $\mathrm{HCl}$ at $\mathrm{pH} 7.4,5 \%$ Ficoll, 5\% SDS, $25 \mathrm{~mm}$ dithiothreitol, 1\% 2-mercaptoethanol, bromphenol blue) at a concentration of $\sim 10 \mu \mathrm{g} / \mu \mathrm{l}$. After heating at $95^{\circ} \mathrm{C}$ for $5 \mathrm{~min}$, the samples were pushed through a $25-$ gauge needle to reduce viscosity and were centrifuged at room temperature for $2 \mathrm{~min}$. The supernatants were divided into several aliquots and stored at $-70^{\circ} \mathrm{C}$.

\section{Western blotting}

Samples were electrophoresed in SDS $4-6 \%$ polyacrylamide gels, transferred electrophoretically to nitrocellulose membranes (e.g., Weeks et al. 1982), and processed following the manufacturer's protocols (Tropix, Inc.). Membranes were dried at $37^{\circ} \mathrm{C}$ for $10 \mathrm{~min}$, rinsed several times with wash buffer (PBS, $0.1 \%$ Tween $\left.20,0.02 \% \mathrm{NaN}_{3}\right)$, blocked with blocking buffer $(0.2 \%$ I-Block Reagent in wash buffer), rinsed again with wash buffer, and reacted with primary antibodies for $1-2 \mathrm{hr}$ at room temper- ature or overnight at $4^{\circ} \mathrm{C}$. Bound primary antibody was detected by alkaline phosphatase-conjugated secondary antibody, followed by reaction with the chemiluminescent substrate AMPPD (Tropix, Inc.) or, in some cases, with Nitroblue tetrazolium (NBT, $100 \mu \mathrm{g} / \mathrm{ml}$ ) and 5-bromo-4-chloro-3-indolyl phosphate (BCIP, $50 \mu \mathrm{g} / \mathrm{ml}$ ) in $50 \mathrm{~mm}$ Tris- $\mathrm{HCl}, 50 \mathrm{~mm} \mathrm{MgCl}{ }_{2}$ (pH 9.6).

\section{Phosphatase treatment of PCTD fusion protein}

Twenty-five-nanogram samples of PCTD fusion protein were incubated at $37^{\circ} \mathrm{C}$ with varying amounts of alkaline phosphatase in dephosphorylation buffer $150 \mathrm{~mm}$ Tris- $\mathrm{HCl}, 0.1 \mathrm{~mm}$ EDTA at $\mathrm{pH} 8.5$ ) for $2 \mathrm{hr}$; reactions were stopped by adding $15 \mu \mathrm{l}$ of SDS sample buffer and placing on dry ice. A control contained no phosphatase. The samples were then heated at $95^{\circ} \mathrm{C}$ for $5 \mathrm{~min}$ and subjected to Western blot analysis.

\section{Polytene chromosome preparations}

We find the following procedure to be convenient and the results obtained to be reproducible and essentially identical to those obtained with somewhat different methods (Silver and Elgin 1976; Weeks et al. 1982; Clark et al. 1991, and references therein; Zink et al. 1991). Late third- instar larvae, grown on modified Instant Drosophila Medium (Greenleaf et al. 1979) at room temperature $\left(22 \pm 2^{\circ} \mathrm{C}\right)$, were dissected in PBS $+0.5 \%$ Triton $\mathrm{X}-100$ (PBS $=10 \mathrm{~mm}$ sodium phosphate at $\mathrm{pH} 7.2+0.85 \%$ $\mathrm{NaCl}_{\text {; }}$ all steps at room temperature unless indicated otherwise). Salivary glands were picked up in $\sim 4 \mu$ l of solution with a mechanical pipettor and transferred into $\sim 0.5 \mathrm{ml}$ of fresh PBS $+0.5 \%$ Triton X-100 in one well of a Pyrex Spot Test Plate. The glands were then transferred to another well of the plate containing $\sim 0.5 \mathrm{ml}$ of PBS $+0.5 \%$ Triton $\mathrm{X} \cdot 100+3.7 \%$ formaldehyde, fixed for $\sim 30 \mathrm{sec}$, and then rinsed again in fresh PBS $+0.5 \%$ Triton X-100. The fixed glands were transferred to another well of the plate containing $45 \%$ acetic acid $+1 \%$ formaldehyde, then picked up in $\sim 9.0 \mu \mathrm{l}$ and placed on a siliconized $18 \times 18-\mathrm{mm}$ glass coverslip. Chromosome spreads were prepared by placing the coverslip on a microscope slide and tapping with the eraser end of a pencil. These spreads were then squashed and placed on a block of dry ice for several minutes. The coverslip was popped off with a razor blade, and the slide was placed in PBS $+0.1 \%$ Tween 20 (PBS-Tw) for $\geqslant 30 \mathrm{~min}$. At this point, slides were either subjected to antibody staining or transferred to PBS-Tw $/ 50 \%$ ethylene glycol and stored at $-20^{\circ} \mathrm{C}$. Note that a control experiment with Pol II, in which we varied the fixation time (in the $3.7 \% \mathrm{HCHO}$ ) from 0 to $120 \mathrm{sec}$, indicated that fixation was essentially complete (i.e., maximum fluorescence was attained) by $10 \mathrm{sec}$.

For heat shock preparations, third-instar larvae were heat shocked at $37^{\circ} \mathrm{C}$ (in a closed $1.5-\mathrm{ml}$ microcentrifuge tube submerged in a water bath) for the desired time and then dissected quickly as described above. For heat shocks of 30-90 sec, salivary glands were removed as descrubed above, submerged in $\mathrm{PBS}+0.5 \%$ Triton $\mathrm{X}-100$ at $37^{\circ} \mathrm{C}$ for the desired time, and transferred immediately to fixative.

\section{Antibody staining}

The squash preparations were rinsed with PBS-Tw and then blocked for $30 \mathrm{~min}$ in PBS-Tw $+4 \%$ normal donkey serum (NDS) (these and subsequent steps at room temperature). The slides were then rinsed briefly in PBS-Tw and incubated with the primary antibodies in PBS-Tw /dilutions between 1:10 and $1: 1000$; final concentrations for affinity-purified IgG usually $\sim 1-5 \mu \mathrm{g} / \mathrm{ml}$ ) for $45-60 \mathrm{~min}$. The slides were washed in PBS-Tw 
at least three times for 10 min each time and blocked again as described above. The slides were then incubated with the secondary antibodies (see above) in PBS-Tw (generally at $\sim 1 \mu \mathrm{g} / \mathrm{ml}$ ) for 45-60 min and, after incubation, were again washed as described above. At this point, the slides were stored in PBS-Tw for short times (a few hours or less) or in PBS $/ 50 \%$ ethylene glycol at $-20^{\circ} \mathrm{C}$ for longer times. In cases where DAPI staining was required, after the last wash, the slides were stained with a solution of DAPI $(10 \mathrm{ng} / \mathrm{ml})$ in PBS-Tw for 30-60 sec and washed again with PBS-Tw.

\section{Indirect immunofluorescence microscopy}

A coverslip was mounted using $70 \%$ glycerol, $0.03 \mathrm{M}$ Tris at $\mathrm{pH}$ $9+2.5 \%$ n-propyl gallate, and the chromosome preparations were viewed with a Zeiss Axiophot microscope through a Zeiss $40 \times$ Plan-NEOFLUAR objective (oil immersion, NA 1.4). Images were captured using a Photometrics STAR I Cooled CCD Imaging System and Signal Analytics Corp. IPLab SpectrumPMI v. 2.2.0 software running on a Macintosh Quadra 950. Subsequent image processing was carried out using Adobe Systems, Inc., Photoshop v. 2.0.1 on Macintosh hardware. Images were sharpened, scaled, pseudocolored, and overlaid; they were not edited internally. Frequently, $0.5-\mu \mathrm{m}$ latex beads that fluoresce in all three channels used were included in the mounting me dium to facilitate precise alignment of the images (e.g., Rykowski et al. 1988).

\section{Acknowledgments}

We thank Michael Sheet $z$ for the use of the fluorescence microscope facility and Ron Sterba for much assistance. A.L.G. thanks Mary Rykowski (University of Arizona, Tucson) for assistance, instruction, and encouragement at an early stage in the project. We also thank Yair Argon and Susan Hester for help with the Comprehensive Cancer Center Confocal Microscopy Shared Resource. We are grateful to the following people for providing antibodies: Carl Wu, Sallie Hoch, Paul Agris and Steven Pelsue, Ann Beyer, Sally Amero, Robert Weinzierl and Robert Tjian, David Gilmour, James Kadonaga, and Erika Matunis and Gideon Dreyfuss. For reading the manuscript and helpful comments we thank John Lis, Carl Wu, and Mark Mortin. We thank Paul Modrich for the use of his CCD camera, and June Brickey for help with embryo extracts. This research was supported by National Institutes of Health grants to A.L.G.

The publication costs of this article were defrayed in part by payment of page charges. This article must therefore be hereby marked "advertisement" in accordance with 18 USC section 1734 solely to indicate this fact.

\section{Note added in proof}

Color figures have been deposited into Flybase located in the IU Bio Server. See folder (Sub Dir) John Weeks under Images under allied-data.

\section{References}

Allison, L.A., J.K. Wong, V.D. Fitzpatrick, M. Moyle, and C.J. Ingles. 1988. The C-terminal domain of the largest subunit of RNA polymerase II of Saccharomyces cerevisiae, Drosophila melanogaster, and mammals: A conserved structure with an essential function. Mol. Cell. Biol. 8: 321-329.

Ashburner, M. and J.J. Bonner. 1979. The induction of gene activity in Drosophila by heat shock. Cell 17: 241-254.

Ashburner, M. and G. Richards. 1976. The role of ecdysone in the control of gene activity in the polytene chromosomes of
Drosophila. In Insect development. (ed. P.A. Lawrence) pp. 203-225. Wiley, New York.

Bartholomew, B., M.E. Dahmus, and C.F. Meares. 1986. RNA contacts subunits IIo and IIc in HeLa RNA polymerase II transcription complexes. J. Biol. Chem. 261: 14226-14231.

Bartolomei, M.S., N.F. Halden, C.R. Cullen, and J.L. Corden. 1988. Genetic analysis of the repetitive carboxy-terminal domain of the largest subunit of mouse RNA polymerase II. Mol. Cell. Biol. 8: 330-339.

Beyer, A.L. and Y.N. Osheim. 1988. Splice site selection, rate of splicing, and alternative splicing on nascent transcripts. Genes \& Dev. 2: 754-765.

Billings, P.B., R.W. Allen, F.C. Jensen, and S.O. Hoch. 1982. Anti-RNP monoclonal antibodies derived from a mouse strain with lupus-like autoimmunity. I. Immunol. 128: 1176-1180.

Buermeyer, A.B., N.E. Thompson, L.A. Strasheim, R.R. Burgess, and P.J. Farnham. 1992. The HIPl initiator element plays a role in determining the in vitro requirement of the dihydrofolate reductase gene promoter for the C-terminal domain of RNA polymerase II. Mol. Cell. Biol. 12: 2250-2259.

Buratowski, S. and P.A. Sharp. 1990. Transcription initiation complexes and upstream activation with RNA polymerase II lacking the C-terminal domain of the largest subunit. Mol. Cell. Biol. 10: 5562-5564.

Burtis, K.C., C.S. Thummel, C.W. Jones, F.D. Karim, and D.S. Hogness. 1990. The Drosophila 74EF early puff contains E74, a complex ecdysone-inducible gene that encodes two etsrelated proteins. Cell 61: 85-99.

Cadena, D.L. and M.E. Dahmus. 1987. Messenger RNA synthesis in mammalian cells is catalyzed by the phosphorylated form of RNA polymerase II. J. Biol. Chem. 262: 12468-12474.

Chesnut, J.D., J.H. Stephens, and M.E. Dahmus. 1992. The interaction of RNA polymerase II with the adenovirus- 2 major late promoter is precluded by phosphorylation of the C-ter minal domain of subunit IIa. J. Biol. Chem. 267: 10500-10506.

Clark, R.F., C.R. Wagner, C.A. Craig, and S.C.R. Elgin. 1991 Distribution of chromosomal proteins in polytene chromosomes of Drosophila. Methods Cell Biol. 35: 203-227.

Corden, J.L. 1990. Tails of RNA polymerase II. Trends. Biochem. Sci. 15: 383-387.

Dahmus, M.E. and W.S. Dynan. 1992. Phosphorylation of RNA polymerase II as a transcriptional regulatory mechanism. In Transcriptional regulation. (ed. K. Yamamoto and S. McKnight) vol. 1, pp. 109-129. Cold Spring Harbor Laboratory Press, Cold Spring Harbor, New York.

DiBello, P.R., D.A. Withers, C.A. Bayer, J.W. Fristrom, and G.M. Guild. 1991. The Drosophila Broad-Complex encodes a fam ily of related proteins containing zinc fingers. Genetics 129: 385-397.

Dvir, A., L.Y. Stein, B.L. Calore, and W.S. Dynan, 1993. Purification and characterization of a template-associated protein kinase that phosphorylates RNA polymerase II. I. Biol. Chem. 268: 10440-10447.

Gall, J.G. 1991. Spliceosomes and snurposomes. Science 252: 1499-1500.

Giardina, C., R.M. Perez, and J.T. Lis. 1992. Promoter melting and TFIID complexes on Drosophila genes in vivo. Genes \& Dev. 6: 2190-2200.

Gileadi, O., W.J. Feaver, and R.D. Kornberg. 1992. Cloning of a subunit of yeast RNA polymerase II transcription factor $b$ and CTD kinase. Science 257: 1389-1392.

Gilmour, D.S. and J.T. Lis. 1986. RNA polymerase II interacts with the promoter region of the noninduced hsp70 gene in Drosophila melanogaster cells. Mol. Cell. Biol. 6: 3984 3989. 
Greenleaf, A.L. 1993. Positive patches and negative noodles: Linking RNA processing to transcription? Trends. Biochem. Sci. 18: 117-119.

Greenleaf, A.L., U. Plagens, and E.K.F. Bautz. F. 1976. Localization of RNA polymerase on Drosophila polytene chromosomes by indirect immunofluorescence. In Molecular mechanisms in the control of gene expression (ed. D.P. Nierlich, W.J. Rutter and C.F. Fox), vol. 5, pp. 249-254. Academic Press, New York.

Greenleaf, A.L., L.M. Borsett, P.F. Jiamachello, and D.E. Coulter. 1979. Alpha-amanitin-resistant D. melanogaster with an altered RNA polymerase II. Cell 18: 613-622.

Guilfoyle, T.J. 1989. A protein kinase from wheat germ that phosphorylates the largest subunit of RNA polymerase II. Plant Cell 1: 827-836.

Hansen, J.C. and J. Ausio. 1992. Chromatin dynamics and the modulation of genetic activity. Trends. Biochem. Sci. 17: 187-191.

Jamrich, M., A.L. Greenleaf, and E.K. Bautz. 1977. Localization of RNA polymerase in polytene chromosomes of Drosophila melanogaster. Proc. Natl. Acad. Sci. 74: 2079-2083.

Jimenez-Garcia, L.F. and D.L. Spector. 1993. In vivo evidence that transcription and splicing are coordinated by a recruiting mechanism. Cell 73: 47-59.

Kim, W.Y. and M.E. Dahmus. 1986. Immunochemical analysis of mammalian RNA polymerase II subspecies. Stability and relative in vivo concentration. $I$. Biol. Chem. 261: 1421914225.

- 1989. The major late promoter of adenovirus-2 is accurately transcribed by RNA polymerases IIO, IIA, and IIB. $J$. Biol. Chem. 264: 3169-3176.

Koleske, A.J., S. Buratowski, M. Nonet, and R.A. Young. 1992. A novel transcription factor reveals a functional link between the RNA polymerase II CTD and TFIID. Cell 69: 883894.

Kolodziej, P.A., N. Woychik, S.M. Liao, and R.A. Young. 1990. RNA polymerase II subunit composition, stoichiometry, and phosphorylation. Mol. Cell. Biol. 10: 1915-1920.

Laybourn, P.J. and M.E. Dahmus. 1990. Phosphorylation of RNA polymerase IIA occurs subsequent to interaction with the promoter and before the initiation of transcription. $I$. Biol. Chem. 265: 13165-13173.

Lee, H., K.W. Kraus, M.F. Wolfner, and J.T. Lis. 1992. DNA sequence requirements for generating paused polymerase at the start of hsp70. Genes \& Dev. 6: 284-295.

Lee, J.M. and A.L. Greenleaf. 1989. A protein kinase that phosphorylates the C-terminal repeat domain of the largest subunit of RNA polymerase II. Proc. Natl. Acad. Sci. 86: 36243628.

- 1991. CTD kinase large subunit is encoded by CTK1, a gene required for normal growth of Saccharomyces cerevisiae. Gene Expression 1: 149-167.

Legagneux, V., M. Morange, and O. Bensaude. 1990. Heat-shock and related stress enhance RNA polymerase II C-terminaldomain kinase activity in HeLa cell extracts. Eur. J. Biochem. 193: 121-126.

Lemaire, M.F. and C.S. Thummel. 1990. Splicing precedes polyadenylation during Drosophila E74A transcription. Mol. Cell. Biol. 10: 6059-6063.

Lis, J.T., J.A. Simon, and C.A. Sutton. 1983. New heat shock puffs and beta-galactosidase activity resulting from transformation of Drosophila with an hsp70-lacZ hybrid gene. Cell 35: 403-410.

Lu, H., O. Flores, R. Weinmann, and D. Reinberg. 1991. The nonphosphorylated form of RNA polymerase II preferentially associates with the preinitiation complex. Proc. Natl.
Acad. Sci. 88: 10004-10008.

Lu, H., L. Zawel, L. Fisher, J.M. Egly, and D. Reinberg. 1992. Human general transcription factor IIH phosphorylates the C-terminal domain of RNA polymerase II. Nature 358: 641645.

Matunis, M.J., E.L. Matunis, and G. Dreyfuss. 1992. Isolation of hnRNP complexes from Drosophila melanogaster. I. Cell. Biol. 116: 245-255.

Nonet, M., D. Sweetser, and R.A. Young. 1987. Functional redundancy and structural polymorphism in the large subunit of RNA polymerase II. Cell 50: 909-915.

O'Brien, T. and J.T. Lis. 1991. RNA polymerase II pauses at the $5^{\prime}$ end of the transcriptionally induced Drosophila hsp 70 gene. Mol. Cell. Biol. 11: 5285-5290.

Payne, J.M. and M.E. Dahmus. 1993. Partial purification and characterization of two distinct protein kinases that differentially phosphorylate the carboxy-terminal domain of RNA polymerase subunit IIa. J. Biol. Chem. 268: 80-87.

Pelsue, S., K.D. Jung, and P.F. Agris. 1993. Immunochemical analysis of an arginine-rich systemic lupus erythematosus autoepitope. Autoimmunity, (in press).

Peterson, C.L., W. Kruger, and I. Herskowitz. 1991. A functional interaction between the C-terminal domain of RNA polymerase II and the negative regulator SIN1. Cell 64: 11351143.

Rabindran, S.K., R.I. Haroun, J. Clos, J. Wisniewski, and C. Wu. 1993. Regulation of heat shock factor trimer formation: Role of a conserved leucine zipper. Science 259: 230-234.

Ritossa, F. 1962. A new puffing pattern induced by heat shock and DNP in Drosophila. Experientia 18: 571-573.

Robbins, A., W.S. Dynan, A.L. Greenleaf, and R. Tjian. 1984. Affinity-purified antibody as a probe of RNA polymerase II subunit structure. J. Mol. Appl. Genet. 2: 343-353.

Rougvie, A.E. and I.T. Lis. 1988. The RNA polymerase II molecule at the $5^{\prime}$ end of the uninduced hsp70 gene of D. melanogaster is transcriptionally engaged. Cell 54: 795-804.

1990. Postinitiation transcriptional control in Drosophila melanogaster. Mol. Cell. Biol. 10: 6041-6045.

Rykowski, M.C., S.J. Parmelee, D.A. Agard, and J.W. Sedat. 1988. Precise determination of the molecular limits of a polytene chromosome band: regulatory sequences for the Notch gene are in the interband. Cell 54: 461-472.

Scafe, C., C. Chao, J. Lopes, J.P. Hirsch, S. Henry, and R.A. Young. 1990. RNA polymerase II C-terminal repeat influences response to transcriptional enhancer signals. Nature 347: 491-494.

Segraves, W.A. and D.A. Hogness. 1990. The E75 ecdysone-inducible gene responsible for the 75B early puff in Drosophila encodes two new members of the steroid receptor superfamily. Genes \& Dev. 4: 204-219.

Serizawa, H., R.C. Conaway, and J.W. Conaway. 1992. A carboxy-terminal-domain kinase associated with RNA polymerase II transcription factor delta from rat liver. Proc. Natl. Acad. Sci. 89: 7476-7480.

Serizawa, H., J.W. Conaway, and R.C. Conaway. 1993. Phosphorylation of C-terminal domain of RNA polymerase II is not required in basal transcription. Nature 363: 371-374.

Silver, L.M. and S.C.R. Elgin. 1976. A method for determination of the in situ distribution of chromosomal proteins. Proc. Natl. Acad. Sci. 73: 423-427.

Simon, J.A., C.A. Sutton, and J.T. Lis. 1985. Localization and expression of transformed DNA sequences within heat shock puffs of Drosophila melanogaster. Chromosoma 93: 26-30.

Stevens, A. and M.K. Maupin. 1989. 5,6-Dichloro-1-beta-D-ribofuranosylbenzimidazole inhibits a HeLa protein kinase that 
Weeks et al.

phosphorylates an RNA polymerase II-derived peptide. Biochem. Biophys. Res. Commun. 159: 508-515.

Stone, N. and D. Reinberg. 1992. Protein kinases from Aspergillus nidulans that phosphorylate the carboxy-terminal domain of the largest subunit of RNA polymerase II. J. Biol. Chem. 267: 6353-6360.

Thompson, C.M., A.J. Koleske, D.M. Chao, and R.A. Young. 1993. A multisubunit complex associated with the RNA polymerase II CTD and TATA-binding protein in yeast. Cell 73: 1-20.

Thompson, N.E., T.H. Steinberg, D.B. Aronson, and R.R. Burgess. 1989. Inhibition of in vivo and in vitro transcription by monoclonal antibodies prepared against wheat germ RNA polymerase II that react with the heptapeptide repeat of eukaryotic RNA polymerase II. I. Biol. Chem. 264: 1151111520.

Thummel, C.S., K.C. Burtis, and D.S. Hogness. 1990. Spatial and temporal patterns of $E 74$ transcription during Drosophila development. Cell 61: 101-111.

Usheva, A., E. Maldonado, A. Goldring, H. Lu, C. Houbavi, D. Reinberg, and Y. Aloni. 1992. Specific interaction between the nonphosphorylated form of RNA polymerase II and the TATA-binding protein. Cell 69: 871-881.

Weeks, J.R., D.E. Coulter, and A.L. Greenleaf. 1982. Immunological studies of RNA polymerase II using antibodies to subunits of Drosophila and wheat germ enzyme. I. Biol. Chem. 257: 5884-5892.

Westwood, J.T., J. Clos, and C. Wu. 1991. Stress-induced oligomerization and chromosomal relocalization of heat-shock factor. Nature 353: 822-827.

$\mathrm{Wu}, \mathrm{C} .1984$. Activating protein factor binds in vitro to upstream control sequences in heat shock gene chromatin. $\mathrm{Na}$ ture 311: 81-84.

Xiao, H. and J.T. Lis. 1988. Germline transformation used to define key features of heat-shock response elements. Science 239: 1139-1142.

Xing, Y., C.V. Johnson, P.R. Dobner, and J.B. Lawrence. 1993. Higher level organization of individual gene transcription and RNA splicing. Science 259: 1326-1330.

Young, R.A. 1991. RNA polymerase II. Annu. Rev. Biochem. 60: $689-715$.

Zehring, W.A. and A.L. Greenleaf. 1990. The carboxy-terminal repeat domain of RNA polymerase II is not required for transcription factor $\mathrm{Spl}$ to function in vitro. /. Biol. Chem. 265: 8351-8353.

Zehring, W.A., J.M. Lee, J.R. Weeks, R.S. Jokerst, and A.L. Greenleaf. 1988. The C-terminal repeat domain of RNA polymerase II largest subunit is essential in vivo but is not required for accurate transcription initiation in vitro. Proc. Natl. Acad. Sci. 85: 3698-3702.

Zhang, J. and J.L. Corden. 1991. Identification of phosphorylation sites in the repetitive carboxy-terminal domain of the mouse RNA polymerase II largest subunit. I. Biol. Chem. 266: 2290-2296.

Zink, B., Y. Engstrom, W.J. Gehring, and R. Paro. 1991. Direct interaction of the polycomb protein with Antennapedia regulatory sequences in polytene chromosomes of Drosophila melanogaster. $E M B O$ I. 10: 153-162. 


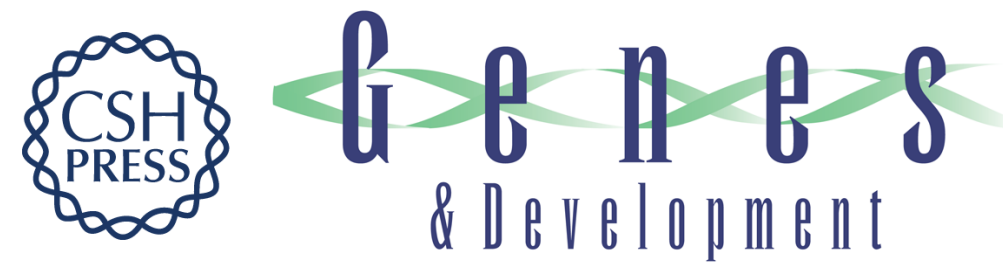

\section{Locus-specific variation in phosphorylation state of RNA polymerase II in vivo: correlations with gene activity and transcript processing.}

J R Weeks, S E Hardin, J Shen, et al.

Genes Dev. 1993, 7:

Access the most recent version at doi:10.1101/gad.7.12a.2329

References This article cites 70 articles, 41 of which can be accessed free at:

http://genesdev.cshlp.org/content/7/12a/2329.full.html\#ref-list-1

License

Email Alerting Receive free email alerts when new articles cite this article - sign up in the box at the top Service right corner of the article or click here.

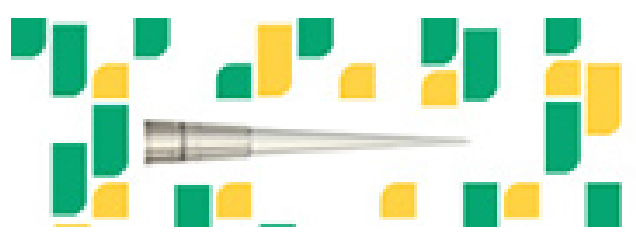

Focused on your science. 